NBER WORKING PAPER SERIES

\title{
HOW DOES MACROPRUDENTIAL REGULATION CHANGE BANK CREDIT SUPPLY?
}

\author{
Anil K Kashyap \\ Dimitrios P. Tsomocos \\ Alexandros P. Vardoulakis \\ Working Paper 20165 \\ http://www.nber.org/papers/w20165
NATIONAL BUREAU OF ECONOMIC RESEARCH
1050 Massachusetts Avenue
Cambridge, MA 02138 \\ May 2014
}

We are grateful to John Geanakoplos, Frank Smets and seminar participants at the Norges Bank, Board of Governors of the Federal Reserve, Wisconsin School of Business, Chicago Booth, the International Monetary Fund, the Bank of England and the 10th Annual GE Cowles conference for comments. Kashyap thanks the Initiative on Global Markets at the University of Chicago Booth School of Business and the National Science Foundation for a grant administered by the National Bureau of Economic Research for research support. Kashyap's disclosures of his outside compensated activities are available on his web page. All errors herein are ours. The views expressed in this paper are those of the authors and do not necessarily represent those of Federal Reserve Board of Governors, anyone in the Federal Reserve System, any of the institutions with which we are affiliated, or the National Bureau of Economic Research.

NBER working papers are circulated for discussion and comment purposes. They have not been peerreviewed or been subject to the review by the NBER Board of Directors that accompanies official NBER publications.

(C) 2014 by Anil K Kashyap, Dimitrios P. Tsomocos, and Alexandros P. Vardoulakis. All rights reserved. Short sections of text, not to exceed two paragraphs, may be quoted without explicit permission provided that full credit, including $(\mathcal{C}$ notice, is given to the source. 
How does macroprudential regulation change bank credit supply?

Anil K Kashyap, Dimitrios P. Tsomocos, and Alexandros P. Vardoulakis

NBER Working Paper No. 20165

May 2014

JEL No. E44,G01,G21,G28

\begin{abstract}
$\underline{\text { ABSTRACT }}$
We analyze a variant of the Diamond-Dybvig (1983) model of banking in which savers can use a bank to invest in a risky project operated by an entrepreneur. The savers can buy equity in the bank and save via deposits. The bank chooses to invest in a safe asset or to fund the entrepreneur. The bank and the entrepreneur face limited liability and there is a probability of a run which is governed by the bank's leverage and its mix of safe and risky assets. The possibility of the run reduces the incentive to lend and take risk, while limited liability pushes for excessive lending and risk-taking. We explore how capital regulation, liquidity regulation, deposit insurance, loan to value limits, and dividend taxes interact to offset these frictions. We compare agents welfare in the decentralized equilibrium absent regulation with welfare in equilibria that prevail with various regulations that are optimally chosen. In general, regulation can lead to Pareto improvements but fully correcting both distortions requires more than one regulation.
\end{abstract}

\author{
Anil K Kashyap \\ Booth School of Business \\ University of Chicago \\ 5807 S. Woodlawn Avenue \\ Chicago, IL 60637 \\ and NBER \\ anil.kashyap@chicagobooth.edu \\ Dimitrios P. Tsomocos \\ Saïd Business School and St. Edmund Hall \\ University of Oxford \\ Dimitrios.Tsomocos@sbs.ox.ac.uk
}

\author{
Alexandros P. Vardoulakis \\ Board of Governors of the Federal Reserve System \\ alexandros.vardoulakis@frb.gov
}

An online appendix is available at:

http://www.nber.org/data-appendix/w20165 


\section{Introduction}

In this paper we expand the Diamond and Dybvig (1983) model of banking in five ways to make it conducive to exploring various macroprudential regulations that have been discussed in the wake of the recent Global Financial Crisis (GFC). The first change is to introduce 3 types of agents: savers, bankers, and entrepreneurs. A second change is that the entrepreneurs operate a risky technology. The third change is that savers face a portfolio decision in which they can directly invest in a safe asset or invest in the bank in the form of either deposits or equity. Fourth, we posit that banks and the entrepreneurs are subject to limited liability. Finally, we modify the model in the spirit of Goldstein and Pauzner (2005) so that whether or not a run occurs is tied to the funding structure and lending choices of the bank.

These modifications mean that banks play three roles in the economy. First, they help provide liquidity insurance for savers. Second, they improve the risk sharing opportunities for savers (relative to the case where direct lending to borrowers was required). Third, because of the better risk sharing, they expand the amount of funding available to borrowers. These are the three leading functions that various theories suppose that banks play.

Furthermore, the model not only succinctly nests competing visions of the causes of the GFC, but also can be used to explore potential regulatory tools that are currently being proposed to prevent future crises. In particular, Admati and Hellwig (2013) and many other observers argue that the GFC was largely due to excessive risk-taking by under-capitalized banks which were exploiting taxpayer support. The limited liability assumption combined with the option for entrepreneurs to invest in a risky technology insures that this force is present in the model. In isolation, these features will lead to over-investment and excessive risk-taking.

A second view, reflected in the French et al. (2010) and elsewhere, holds that the central problem exposed by the GFC was funding vulnerabilities in the financial system and that runs debilitated the ability of the financial system to intermediate. The Diamond-Dybvig framework is designed to study this possibility. The fact that savers may demand their money back before loans would normally be repaid makes banks cautious in their lending. If a run does occur it is destructive because loans must be recalled to service deposits and both savers, who may not be repaid, and borrowers are worse off. This aspect of the model creates a force for under-investment (or equivalently too little lending).

By giving savers and the banks a portfolio choice the model is suitable for studying many types of regulations including capital regulation, liquidity regulation, deposit insurance, loan to value limits, and dividend taxes. Because we do a full general equilibrium analysis in which agents choose when to default and when to run on the bank, we can study not only the direct effects that result from these regulations, but also those that arise through general equilibrium price effects.

We reach three main conclusions from analyzing a calibrated version of this model. First, when a run occurs it is sufficiently debilitating that preventing it via regulation can lead all agents in the model to be better off than in a decentralized equilibrium with no regulation. In other words, the decentralized (or equivalently competitive) equilibrium in the model is constrained Pareto inefficient 
and can be improved upon by various regulatory interventions. ${ }^{1}$

In the analysis we compare the decentralized allocations to two types of other equilibria. One involves a central planner who can directly choose allocations and internalizes all general equilibrium effects, but is constrained by the existing market structure. We call this the second best benchmark and in computing it we do not worry about how the planner would have to decentralize the solution.

We also study other equilibria where a planner allows agents to choose allocations, but intervenes by imposing limits on certain quantities (e.g. bank capital ratios) or prices (e.g. a dividend tax) to affect the agents' marginal decisions. We dub these equilibria "dual planning" outcomes. The more precise statement of the first result is that Pareto improvements over the competitive equilibrium are possible even if the planner considers only dual planning outcomes.

In the original Diamond-Dybvig model a bank run occurs randomly. We assume instead that when the bank substitutes equity financing for deposit financing it lowers the risk of a run. Similarly, when it holds more of the safe asset and makes few loans it lowers the risk of a run. Our assumptions are consistent with the analysis of Goldstein and Pauzner (2005) variant of the Diamond-Dybvig model.

Our second result is that various regulatory tools can alleviate the run risk in very different ways because once a regulation is imposed the bank and savers will endogenously alter their other portfolio choices. For instance, raising capital requirements forces the bank to adjust deposit interest rates to attract more equity funding (and less deposit funding) from the savers. On its own this change will lower the risk of a run. But, in response the bank may choose to take more risk on the asset side of its balance sheet by reducing its holding of safe assets and making more loans. Deposit insurance always creates an incentive to do more lending. So it is possible that regulations that moderate the risk of a run exacerbate the problems caused by limited liability.

The last result is that once a single regulatory tool has been used to alleviate the risk of a run, further Pareto improvements are not possible. The problem comes because the entrepreneurs naturally want to take more risk to exploit the protection of limited liability. Once the entrepreneurs no longer worry that the run risk is present, there are no further interventions that can improve their welfare. Hence, additional regulation only makes sense to impose because of the desire to redistribute income.

Depending on how a social planner compares the importance of the bankers, savers and entrepreneurs additional regulation may or may not be attractive. A corollary to this conclusion is that whether or not optimal regulation lowers or raises investment also depends on the planner's weights on the different agents. We characterize the combinations of regulations that can be used to most

\footnotetext{
${ }^{1}$ In a model with Diamond-Dybvig preferences and complete asset markets for aggregate risk, Allen and Gale (2004) show that equilibrium allocations under financial intermediation are constrained efficient. In our framework, the presence of incomplete markets and limited liability makes the capital structure of banks matter for equilibrium outcomes and bank-run risk. The optimality conditions of a constrained planner will differ from those in the competitive economy and welfare improvements are possible. See Stiglitz (1982), Geanakoplos and Polemarchakis (1986) and Citana et al. (1998) for a discussion and rigorous proof of constrained Pareto suboptimality. See Brunnermeier and Sannikov (2012) for a related model in which banks play all three roles that we posit, but note that they do not allow for limited liability and bank-runs which will be important in our set up.
} 
closely mimic the dual planning allocations.

The remainder of the paper is separated into five parts. Section 2 introduces the basic model and solves for optimal lending and investment decisions for the saver, the banker and the entrepreneur. Section 3 derives the optimization problem of the constrained social planner, and compares the competitive allocations to the second best solution. Section 4 studies the how various macroprudential regulations change the decisions of the bank, the entrepreneur and the saver, and compare optimal dual planning outcomes to the second best. Section 5 concludes.

\section{Model}

We start by describing the basic structure of the model and then turn to the precise solution of the agents optimal choices. We consider an economy which lasts for three periods, $t=1,2,3$ and is populated by a continuum of three types of agents, entrepreneurs $P$, savers $R$ and bankers $B$. All agents are endowed with a perishable good in the first period, and receive a second such endowment in either the second or third periods depending on their type. All agents are risk-averse.

In period $1, P$ decides how much of his endowment to consume or to invest in a risky project. The project matures in period 3 and delivers an uncertain payoff. There are $S$ states of the world and the true state is revealed in the beginning of the third period. $P$ can also borrow from $B$ in order to invest. $P$ exclusively owns the rights to the risky project, which requires his special skills to operate the technology and produce output. In other words, $R$ and $B$ can only access the technology by lending to $P$. We assume that $P$ can only borrow through simple, non-contingent, non-recourse debt contracts. We will show that in general $P$ will not want to issue equity claims. Apart from the risky project, there is also a riskless asset in the economy, which is in perfectly elastic supply and its yield is normalized to zero.

While loans will not be indexed to the state of the world, they will be collateralized by the total output of the risky project. If the value of the output is higher than the contractually promised repayment, then $P$ honors his obligation. But, $P$ will default on his loan when the value of output is lower than the contractually promised repayment and creditors will seize the project's output.

$P$ does not want consume in period 2. In period 3, he consumes his (new) endowment plus what remains from the project's output after repaying (or defaulting on) his loan. In the event of default, limited liability allows $P$ to consume all of his endowment.

In period $1, R$ decides how much to consume and how to allocate his remaining endowment between investing in the riskless asset, or making an equity investment or deposit in a bank. In period 2 , each agent $R$ receives an additional endowment and learns his type (which is private information and thus non-contractible): With probability $\delta$ the agent is impatient and with probability $1-\delta$ he is patient. $R^{\prime} s$ types are i.i.d. and the law of large numbers means that the aggregate total of impatient savers can be perfectly predicted. Impatient savers can consume only in periods 1 and 2 , while patient ones consume in periods 1 and 3. As in Diamond and Dybvig, banks facilitate risk-sharing by offering demand-deposit contracts, which will be specified below. 
We depart from Diamond and Dybvig by allowing for aggregate uncertainty in period 3. Numerous papers, for example Allen and Gale (2004), Rochet and Vives (2004), Goldstein and Pauzner (2005), model aggregate uncertainty in the Diamond-Dybvig model. We differ from these papers because we assume incomplete asset markets for aggregate risk and we allow banks to fund themselves with both debt and equity. Since entrepreneurs sometimes default, loans are risky and splitting the risk between deposits and equity allows agents to partially hedge this risk. ${ }^{2}$ To simplify the presentation of the results while preserving market incompleteness, we will consider only three states of the world in the third period of the model. These will be calibrated in our numerical analysis to cover the three interesting economic cases. One state features full repayment, the second involves a partial default, while in the third the bank fails. Allowing for more possible outcomes will not overturn the fundamental insights from the simplified model.

$B$ is a banker, who in addition to her period 1 endowment, owns a financial intermediary with some initial capital. She can raise additional equity or accept deposits from $R$. The initial equity inside the bank cannot be used for first period consumption. The bank's shareholders are protected by limited liability. Dividends on equity are paid pro-rata after deposits have been fully repaid. Otherwise, bankruptcy occurs, equity holders receive nothing and the salvage value of the bank's assets are distributed pro-rata to depositors. The banker is assumed to make two separate decisions, with one side of her brain she manages the assets of the bank, and the other side decides what to do with her endowment, which she can invest as additional equity or deposits in the bank or consume in period $1 .^{3}$ Like $P, B$ always prefers to consume in period 3 .

The bank offers different interest rates on early and late deposit withdrawals, denoted by $r_{2}^{D}$ and $r_{3}^{D}$, respectively, where $r_{2}^{D}<r_{3}^{D}$. Impatient savers will withdraw their deposits in period 2, while the bank will set $r_{2}^{D}$ so that patient ones have an incentive to wait until period 3. We assume that the loan, $I$, to entrepreneurs can be called at $t=2$ subject to a liquidation cost $1-\xi$ per unit of lending. We parametrise $\xi$ such that early liquidation is inefficient and the bank would rather invest in enough liquid assets in period $1, L I Q_{1}$, to service the expected the expected level of withdrawals by impatient depositors. If the bank cannot fully serve early deposit withdrawals, shareholders are wiped-out, the bank's assets are liquidated and distributed to the depositors that decided to withdraw early given a sequential service constraint. Thus, there is an endogenous demand for holding the liquid asset.

The sequential service constraint can also give rise to a bank-run equilibrium where all patient savers decide to withdraw early. A bank run can occur if the liquidation value of the bank, $L I Q_{1}+$ $\xi \cdot I$ is lower than the total deposits outstanding in period $2, D^{R}\left(1+r_{2}^{D}\right)$, which can only happen if $\xi$ is sufficiently low or if $r_{2}^{D}$ is sufficiently high; notice that if $\xi=1$ and $r_{2}^{D}=0$ the value of the total assets is always higher than outstanding deposits because of the bank's equity. Thus, $r_{2}^{D}>0$ is not

\footnotetext{
${ }^{2}$ See Benston and Smith (1976) and Allen and Gale (1997) for models that rationalize this role for banks.

${ }^{3}$ The model allows for the possibility that $B$ deposits some of her initial endowment in the bank as well. $B$ always waits until period 3 to withdraw her deposits. For simplicity of exposition, we consider a calibrated example where $B$ is not wealthy enough in period 1 to want to invest in deposits or hold any liquid assets, which reduces her role to managing the bank.
} 
a sufficient condition for the existence of bank-run equilibria and we require liquidation costs to be positive contrary to Diamond and Dybvig (1983). ${ }^{4}$

As in Diamond and Dybvig, bank-runs in our model are panic based rather than purely information based as in Chari and Jagannathan (1988), Jacklin and Bhattacharya (1988), Allen and Gale (1998) and Uhlig (2010). In other words, a bank-run can occur due to a coordination problem among depositors even if the bank is solvent in the long-run. In determining the optimal ex-ante decisions, it is important to know what determines panics. In the Diamond-Dybvig model panics happen purely by chance. Cooper and Ross (1998) suppose instead that with exogenous probability $q$ there is a wave of economy-wide pessimism which governs whether a panic occurs (Peck and Shell (2003) assume that the probability of a bank-run is driven by sunspots; Gertler and Kiyotaki (2013) model it as an autoregressive process). We modify the Cooper and Ross assumption so that $q$ is a function of the balance sheet structure of the bank.

We use a functional form for the probability of a bank-run which is an approximation of the solution in Goldstein and Pauzner (2005), who use global games methods to resolve the multiplicity of equilibria. ${ }^{5}$ In particular, we suppose that the probability of a bank-run is given by

$$
q=\left(\max \left[1-\frac{L I Q_{1}+\xi \cdot I}{D^{R}\left(1+r_{2}^{D}\right)}, 0\right]\right)^{2}
$$

This formulation has several appealing properties. First, as in Goldstein and Pauzner, a run becomes more likely when individual depositors become less likely to be fully repaid during a run. Second, when the liquidation value of the bank, $L I Q_{1}+\xi \cdot I$, exceeds the promised gross delivery on demand deposits, $D^{R}\left(1+r_{2}^{D}\right)$, a run never occurs. Hence, regulation that tries to set $q=0$ can do so by insuring that this condition holds without worrying about the functional form of $q$. Third, the probability of a bank run is decreasing in the bank's liquidity and capital positions, since $\frac{L I Q_{1}+\xi \cdot I}{D^{R}\left(1+r_{2}^{D}\right)}$ can be written as $\frac{L R+\xi}{(1+L R-C R)\left(1+r_{2}^{D}\right)}$, where $L R=L I Q_{1} / I$ is a liquidity ratio, $C R=E Q / I$ is the capital adequacy ratio, and $E Q=I+L I Q_{1}-D^{R}$ is the total equity capital of the bank.

Figure 1 below summarizes the interactions in the model.

\footnotetext{
${ }^{4}$ In a more elaborate model, the bank would securitize a part of its risky loans to obtain liquidity and $\xi$ would be the price that outside investors would be willing to pay for them. In the presence of other frictions, cash-in-market price may prevail and a fire-sales spiral would reduce $\xi$ further.

${ }^{5}$ In an online Appendix we adjust our framework such that depositors receive private noise signals at $t=2$ regarding the probability of the state of the world and solve for the threshold equilibrium as in Morris and Shin (1998). The probability of a bank-run is a function of $\left(L I Q_{1}+\xi \cdot I\right) /\left(D^{R}\left(1+r_{2}^{D}\right)\right)$ and the consumption levels of patient and impatient depositors. Rochet and Vives (2004) delegate the decision to run to fund manager who have a simpler objective and study the ability of a lender of last resort to mitigate the adverse effects of bank-runs. See also Postlewaite and Vives (1987) for an early attempt to endogenize runs.
} 


\begin{tabular}{|c|c|c|}
\hline$t=1$ & $\mathrm{t}=2$ & $\mathrm{t}=3$ \\
\hline $\begin{array}{l}\text { R chooses: } \\
\text { - How much to invest with P, B or } \\
\text { in the riskless asset } \\
\text {-Whether to fund B with deposits } \\
\text { or equity } \\
\text { - How much to consume this } \\
\text { period }\end{array}$ & $\begin{array}{l}\text { R learns whether he is impatient } \\
\text { or not: } \\
\text {-If he is impatient, he withdraws } \\
\text { his deposit and consumes } \\
\text { - If patient, he might run based } \\
\text { on B's riskiness and consume } \\
\text { whatever he can }\end{array}$ & $\begin{array}{l}\text { If a run has not occurred, then } \\
\text { there are } \\
3 \text { outcomes for P's project (High, } \\
\text { Med, Low) } \\
\text { P repays all loans to R \& B (or } \\
\text { defaults) }\end{array}$ \\
\hline $\begin{array}{l}\text { B chooses: } \\
\text {-Whether to make deposits or to } \\
\text { buy bank equity } \\
\text {-Whether to invest in the riskless } \\
\text { asset }\end{array}$ & $\begin{array}{l}\text { B chooses: } \\
\text { - How to service withdrawals, } \\
\text { selling the riskless asset or } \\
\text { liquidating loans }\end{array}$ & $\begin{array}{l}\text { B repays deposits first (or defaults) } \\
\text { and then pays pro-rata dividends } \\
\text { on equity }\end{array}$ \\
\hline $\begin{array}{l}\text {-Scale of the loan to } P \\
\text {-How much to consume this } \\
\text { period }\end{array}$ & $\mathrm{P}$ learns if his loan is called by $B$ & All agents consume \\
\hline $\begin{array}{l}\text { P chooses: } \\
\text { - The scale of the risky investment } \\
\text { - How much to consume this } \\
\text { period }\end{array}$ & & \\
\hline
\end{tabular}

Figure 1: Timeline

\subsection{Entrepreneur P's problem}

$P$ wants to maximize his intertemporal expected utility from consumption, formally

$$
\max \bar{U}^{P}=U^{P}\left(c_{1}^{P}\right)+q \cdot \sum_{s} \omega_{3 s} U^{P}\left(c_{3 s}^{P, \text { run }}\right)+(1-q)\left[\sum_{s} \omega_{3 s} U^{P}\left(c_{3 s}^{P, \text { no-run }}\right)\right]
$$

subject to the following constraints (where the associated Lagrange multipliers on the constraints are shown in parentheses):

$$
c_{1}^{P}+I^{P} \leq e_{1}^{P} \quad\left(\lambda_{1}^{P}\right)
$$

and

$$
c_{3 s}^{P, n o-r u n} \leq \max \left[A_{3 s} F\left(I+I^{P}\right)-I\left(1+r^{I}\right), 0\right]+e_{3 s}^{P} \quad\left(\lambda_{3 s}^{P, n o-r u n}\right)
$$

and

$$
c_{3 s}^{P, r u n} \leq \xi \cdot I^{P}+e_{3 s}^{P} \quad\left(\lambda_{3 s}^{P, r u n}\right)
$$

where $\omega_{3 s}$ is the probability of state $s \in\{g, m, b\}$ occurring at $\mathrm{t}=3$, and $c_{1}^{P}, e_{1}^{P}, c_{3 s}^{P, \text { no-run }}, c_{3 s}^{P \text {,run }}$ and $e_{3 s}^{P}$, are the levels of consumption and endowment in period 1 and state $s$ in period 3 respectively. $P$ funds the project using $I^{P}$ from his endowment and by borrowing an additional amount, $I$, from the bank at an interest rate $r^{I}$. $A_{3 s}$ is the uncertain productivity shock. We specialize the production function to be $F=\left(I+I^{P}\right)^{a} \ell^{1-a}=\left(I+I^{P}\right)^{a}$, with $a \leq 1$ and entrepreneurial skills' supply normalized to 
$\ell=1 .^{6}$

If a bank-run occurs, then $P^{\prime} s$ investment is liquidated, and he receives the liquidation value of his capital contribution, $\xi \cdot I^{P}$, as shown in budget constraint (5). ${ }^{7}$ The optimal choice of consumption implies that $\lambda_{1}^{P}=U^{P^{\prime}}\left(c_{1}^{P}\right), \lambda_{3 s}^{P, \text { no-run }}=(1-q) \cdot \omega_{3 s} U^{P^{\prime}}\left(c_{3 s}^{P, \text { no-run }}\right)$, and $\lambda_{3 s}^{P \text {,run }}=q \cdot \omega_{3 s} U^{P^{\prime}}\left(c_{3 s}^{P, \text { run }}\right)$.

It is convenient to define the percentage repayment on the loan by $V_{3 s}^{I}=\min \left[1, \frac{A_{3 s} F\left(\left(I+I^{P}\right)\right.}{I\left(1+r^{I}\right)}\right]$. We choose the productivity levels, $A_{3 s}$, such that $V_{3 g}^{I}=1$ and $0<V_{2 b}^{I}<V_{2 m}^{I}<1$. In words, this means that the bank loan is fully repaid in the good state, and only a partial repayment is made in the other two states, with a larger default in the bad state than the medium state.

To build intuition, provisionally assume that $I^{P}=0$ (and we will verify that this will indeed be true). Importantly, when $P$ defaults the lender seizes all the output from the project. The lenders will anticipate this possibility and will account for that in choosing the interest rate on loans. But from $P^{\prime} s$ perspective this interest rate is taken as given and $P$ will make his investment decision expecting to repay only in the good state of the nature. Thus, the optimal level of $I$ satisfies,

$$
1+r^{I}=a A_{3 g} I^{a-1}
$$

Substituting this result into the definition of $V_{3 s}^{I}$ further implies that,

$$
V_{3 s}^{I}=\min \left[1, \frac{1}{a} \frac{A_{3 s}}{A_{3 g}}\right]
$$

For the equilibria studied in the rest of the paper, we show, in proposition 3 in the appendix, that $P$ will not issue equity claims in equilibrium. Loosely speaking, this happens because issuing equity would reduce the payoffs to $P$ in the good state in exchange for having to borrow less. But, $P$ is already not paying anything back to the bank in the other states of nature so this kind of transaction is not attractive to $P$.

Finally, provided that $P$ has relatively limited resources it would be natural to expect he will also not invest further in his project. Technically, $I^{P}=0$ requires

$$
\begin{gathered}
\lambda_{1}^{P}>a A_{3 g} I^{a-1} \lambda_{3 g}^{P, \text { no-run }}+\xi \cdot \sum_{s} \lambda_{3 s}^{P, \text { run }} \\
\Rightarrow u^{\prime}\left(e_{1}^{P}\right)>a \cdot(1-q) \cdot \omega_{3 g} U^{P^{\prime}}\left(e_{3 g}^{P}+(1-a) A_{3 g} I^{a}\right) A_{3 g} I^{a-1}+\xi \cdot q \cdot \sum_{s} \omega_{3 s} U^{P^{\prime}}\left(e_{3 s}^{P}\right)
\end{gathered}
$$

In the calibrations we consider $e_{1}^{p}$ is always low enough to satisfy inequality (8).

\footnotetext{
${ }^{6}$ Note that for $a=1, P^{\prime} s$ skills are not required to run the project and $B$ can invest directly in it. In this is a special case, the return to lending will be constant.

${ }^{7}$ This amounts to assuming that when the loan is called, the project is terminated and its resale value is much lower than if it could be continued. Our specification assumes that the contribution of the entrepreneur, $I^{P}$, is also liquidated in a run. We could have extended the model to introduce interim liquidity shocks to the entrepreneur, who would require new funding, as in Fahri and Tirole (2012) in order to better justify this modelling choice. However, this would not materially change our analysis, so we abstract from it.
} 
Another implication of the limited liability for $P$ is that his third period consumption is limited to his endowment whenever he defaults. The only force in the model that limits the incentive to invest as much as possible is the interest rate set by lenders. When the bank is lending, the bank also faces limited liability on its deposits so the interest rate will not fully limit the incentive to gamble.

\subsection{Household R's problem}

$R$ wants to maximize his expected utility taking into consideration that he will be impatient with probability $\delta$ and that a bank-run will occur with probability $q$. In a bank-run, all households will try to get their money out of the bank irrespective of their true type. It is helpful to recognize that any particular saver contemplates four possible outcomes when allocating his savings. He could turn out to be impatient and be fully repaid on deposits, he could patient and not have a run occur, or he could get paid or not irrespective of his type in a bank-run. We define the probability that an individual household will be served in full to be $\theta=\min \left[\frac{L I Q_{1}+\xi \cdot I}{\left(D^{R}+D^{B}\right)\left(1+r_{2}^{D}\right)}, 1\right]$. If a run occurs consumption will be $c_{2 / 3}^{R \text {,run,paid }}$ (where patient households carry over their income to consume in period 3 using the liquid asset). With probability $1-\theta, R$ will receive zero repayment on his deposits conditional on a run occurring, and his consumption, $c_{2 / 3}^{R, \text { run,unpaid }}$ will solely consist of his additional endowment $e_{2}^{R}$ and any liquidity holdings carried over from period 1 . Alternatively, with probability $1-q$ a bank-run does not take place. In this case, with probability $\delta, R$ consumes early, $c_{2}^{R, i, n o-r u n}$, and with probability $1-\delta$, he consumes late, $c_{3 s}^{R, p, n o-r u n}$, after uncertainty has realized in period 3 . Formally, $R$ wants to maximize

$$
\begin{aligned}
\bar{U}^{R}= & U^{R}\left(c_{1}^{R}\right)+q\left[\theta \cdot U^{R}\left(c_{2 / 3}^{R, \text { run,paid }}\right)+(1-\theta) U^{R}\left(c_{2 / 3}^{R, \text { run,unpaid }}\right)\right] \\
& +(1-q)\left[\delta \cdot U^{R}\left(c_{2}^{R, i, n o-\text { run }}\right)+(1-\delta) \cdot \sum_{s} \omega_{3 s} U^{R}\left(c_{3 s}^{R, p, \text { no-run }}\right)\right]
\end{aligned}
$$

subject to the budget constraint in each point in time.

In period 1 savers make identical decisions regarding how to allocate their endowment between consumption, deposits, bank equity and liquid asset holdings:

$$
c_{1}^{R}+P_{e q}^{R} x_{e q}^{R}+D^{R}+L I Q_{1}^{R} \leq e_{1}^{R} \quad\left(\lambda_{1}^{R}\right)
$$

where $x_{e q}^{R}$ is the number of bank equity shares he buys and $D^{R}$ are his deposits. $P_{e q}^{R}$ is the price per share that $R$ is willing to pay to purchase equity. $L I Q_{1}^{R}$ is the investment in a safe/liquid asset with zero yield. This asset is assumed to be in perfectly elastic supply and is akin to a storage technology.

In period 2, each household learns his type. If a bank run does not take place, impatient households withdraw their deposits and sell the equity they hold in a secondary market at the price of $P_{\text {sec. }}{ }^{8}$

\footnotetext{
${ }^{8}$ Jacklin and Bhattacharya (1988) also consider the choice between non traded deposits and traded equity. In their framework, only one of the two will be traded in equilibrium, while in our economy there will be an endogenous debt to equity ratio because savers would like to use both assets to insure against aggregate uncertainty in the final period. Moreover, their model differs ours because they assume limited convertibility of deposits, zero liquidation value for the
} 
They may be holding a liquid asset bought in period 1 and they receive an additional endowment, thus

$$
c_{2}^{R, i, n o-r u n} \leq\left(1+r_{2}^{D}\right) D^{R}+L I Q_{1}^{R}+P_{s e c} x_{e q}^{R}+e_{2}^{R} \quad\left(\lambda_{2}^{R, i, n o-r u n}\right)
$$

Absent a bank run, patient households prefer to wait and withdraw their deposits in period 3 . Equation (35) below shows the incentive compatibility constraint such that patient depositors report their true type. They may decide to buy or sell equity in the secondary market and they determine how much of the liquid asset, $L I Q_{2}^{R}$, to carry over to period 3. They fund the purchase of additional equity, $x_{s e c}^{R}$, and new liquid assets with the existing liquid assets carried over from period 1 and the additional endowment they receive, i.e.,

$$
P_{\text {sec }} x_{\text {sec }}^{R}+L I Q_{2}^{R} \leq L I Q_{1}^{R}+P_{\text {sec }} x_{e q}^{R}+e_{2}^{R} \quad\left(\lambda_{2}^{R, p, n o-r u n}\right)
$$

Finally, once uncertainty is realized, patient households receive dividends per share of $D P S_{3 s}$ and have their deposits repaid in full when the bank is solvent. When the bank is insolvent with probability 1 , which is the case in state $3 b$, it is liquidated and the salvage value of the bank's assets are distributed pro-rata to depositors. Letting $V_{3 s}^{D} \in[0,1]$ be the percentage repayment on period 3 deposit withdrawals, which we define later, implies that consumption will be:

$$
c_{3 s}^{R, p, \text { no-run }} \leq x_{s e c}^{R} D P S_{3 s}+V_{3 s}^{D} D^{R}\left(1+r_{3}^{D}\right)+L I Q_{2}^{R} \quad\left(\lambda_{3 s}^{R, p, n o-r u n}\right)
$$

If there is a bank run then equity holdings are worthless, i.e. $P_{s e c}=0$. Some households will receive their deposit in full and their consumption is given by

$$
c_{2 / 3}^{R, \text { run,paid }} \leq\left(1+r_{2}^{D}\right) D^{R}+L I Q_{1}^{R}+e_{2}^{R} \quad\left(\lambda_{2}^{R \text {,run,paid }}\right)
$$

while the rest will lose their deposits and consume only out of their liquid holdings and their endowment, i.e.,

$$
c_{2 / 3}^{R, \text { run,unpaid }} \leq L I Q_{1}^{R}+e_{2}^{R} \quad\left(\lambda_{2}^{R, \text { run,unpaid }}\right)
$$

Optimal consumption choices imply that $\lambda_{1}^{R}=U^{R^{\prime}}\left(c_{1}^{R}\right), \lambda_{2}^{R, i, n o-r u n}=(1-q) \delta U^{R^{\prime}}\left(c_{2}^{R, i, n o-r u n}\right)$, $\lambda_{2}^{R, \text { run }, \text { paid }}=q \cdot \theta \cdot U^{R^{\prime}}\left(c_{2}^{R, \text { run,paid }}\right), \lambda_{2}^{R, \text { run,unpaid }}=q(1-\theta) U^{R^{\prime}}\left(c_{2}^{R, \text { run }, \text { unpaid }}\right)$ and $\lambda_{3 s}^{R, p, \text { no-run }}=(1-$ $q)(1-\delta) \cdot \omega_{3 s} U^{R^{\prime}}\left(c_{3 s}^{R, p, \text { no-run }}\right)$.

Given our interests in regulation, it is important to understand how savers decide between saving via deposits versus equity. The optimality conditions for investment in deposits and bank equity are:

$$
-\lambda_{1}^{R}+\left(\lambda_{2}^{R, i, n o-r u n}+\lambda_{2}^{R, \text { run,paid }}\right)\left(1+r_{2}^{D}\right)+\sum_{s} \lambda_{3 s}^{R, p, \text { no-run }} V_{3 s}^{D}\left(1+r_{3}^{D}\right)=0
$$

and

$$
-\lambda_{1}^{R} P_{e q}^{R}+\left(\lambda_{2}^{R, i, n o-r u n}+\lambda_{2}^{R, p, n o-r u n}\right) P_{s e c}=0
$$

long-run investment and smooth preference over period 2 and 3 consumption. Our model more closely follows Diamond and Dybvig in these respects. 
Both of these conditions are intuitive. Equation (16) balances the cost of forgoing consumption in the first period against the benefits of investing in demand deposits that provide insurance against the idiosyncratic liquidity shock in the intermediate period as well as the promise of higher (risky) payoff in the long-run if they are not withdrawn early. Equation (17) trades off the cost of forgoing consumption in the first period in order to buy bank equity at a price $P_{e q}^{R}$ which can be sold in the secondary market for $P_{s e c}$ if a bank-run does not occur. If depositors run on the bank $P_{s e c}=0$. So the desire to invest in equity depends on the expected return on holding equity, $\frac{P_{s e c}}{P_{e q}^{R}}$, which is discussed below.

The other period 1 choice for $R$ is to invest in the riskless asset, $L I Q_{1}^{R}$. The optimality condition for this choice is

$$
-\lambda_{1}^{R}+\lambda_{2}^{R, i, n o-\text { run }}+\lambda_{2}^{R, p, \text { no-run }}+\lambda_{2}^{R, \text { run,paid }}+\lambda_{2}^{R, \text { run }, \text { unpaid }} \leq 0,
$$

which holds with inequality when $L I Q_{1}^{R}=0$. This condition simply says the opportunity cost of holding the liquid asset is the forgone consumption in period 1 and those resources can be stored and then turned into a lottery on consumption in the second or third period.

In the second period, if a bank-run does not occur, impatient households consume using their liquid assets, deposits, sales of their equity and their new endowment. The patient households adjust their liquid assets and equity holdings to facilitate consumption in the third period (constraint (12)). The optimality conditions for the liquid asset and equity holdings by patient households in the second period are:

$$
-\lambda_{2}^{R, p, n o-r u n}+\sum_{s} \lambda_{3 s}^{R, p, n o-r u n}=0
$$

and

$$
-\lambda_{2}^{R, p, n o-r u n} P_{s e c}+\sum_{s} \lambda_{3 s}^{R, p, n o-r u n} D P S_{3 s}=0 .
$$

We can now fully characterize $R^{\prime} s$ portfolio decisions. Equations (17) and (18) imply that $R$ will invest in banking equity in the first period only if $P_{s e c}$, given by the discounted sum of future dividends (equation (20)), is higher than $P_{e q}^{R}$. Otherwise he will prefer to hold the liquid asset.

In choosing between investing in the liquid asset or demand deposits in the first period, he assesses the benefits of the partial liquidity insurance in the event of a bank-run that come with deposits, along with their promise of a higher return in the third period, against the certain insurance of the liquid asset. The trade-off can been seen by setting $r_{2}^{D}=0$ and combining equations (16), (19) and (18). ${ }^{9} R$ will not invest in the liquid asset at $\mathrm{t}=1$ if $\lambda_{2}^{R, p, \text { run }}<\sum_{s} \lambda_{3 s}^{R, p, \text { no-run }}\left[V_{3 s}^{D}\left(1+r_{3}^{D}\right)-1\right]$, i.e. if the marginal value of foregone consumption in the third period is higher than the marginal value of higher consumption when $R$ is unlucky and loses all his deposits due to a bank-run.

Finally, constraint (13) says that third period consumption for patient households must be funded from the endowment and returns from the equity, deposits and liquid investments. $R$ would choose

\footnotetext{
${ }^{9}$ Positive $r_{2}^{D}$ for early withdrawals renders deposits more attractive to insure against liquidity shocks. We discuss how $r_{2}^{D}$ is chosen by the bank in section 2.3 .
} 
to invest in both deposits and equity to better smooth consumption across the different states of the world in the third period, thus the capital structure of the bank matters for real outcomes. ${ }^{10}$

\subsection{Banker B's problem}

The banker begins period 1 with an initial endowment, $e_{1}^{B}$, and her ownership in a bank, which we assume she is not able to sell (or sell short). The (exogenously given) initial capital, Etotal ${ }^{B}$, is equally divided among $E^{B}$ shares with a normalized price of 1 . $B$ manages the bank and chooses how to invest its funds.

We allow $B$ to decide how much of her own initial wealth to invest in additional equity and deposits in the bank, $x_{e q}^{B}$ and $D^{B}$, respectively. The additional equity and deposits that $B$ raises from $R$ are denoted by $x_{e q}^{R}$ and $D^{R}$. $B$ issues additional equity at the price of $P_{e q}^{B}$ per share. The bank's assets are divided between a risky loan, denoted by $I$, that is made to $P$ and a liquid (safe) asset, $L I Q_{1}$.

$B$ considers the possibility of a bank run both when she invests her own wealth and in managing the bank, thus wants to maximize her intertemporal expected utility, i.e.,

$$
\begin{aligned}
& \max \bar{U}^{B}=U^{B}\left(c_{1}^{B}\right)+(1-q)\left[\sum_{s} \omega_{3 s} U_{3 s}^{B}\left(c_{3 s}^{B, \text { no-run }}\right)\right] \\
& +q \cdot\left[\theta \sum_{s} \omega_{3 s} U^{B}\left(c_{3 s}^{B, \text { run }, \text { paid }}\right)+(1-\theta) \sum_{s} \omega_{3 s} U^{B}\left(c_{3 s}^{B, \text { run }, \text { unpaid }}\right)\right]
\end{aligned}
$$

First, $B$ decides how to allocate the portion of her wealth which is not trapped as banking equity. This implies

$$
c_{1}^{B}+P_{e q}^{B} x_{e q}^{B}+D^{B}+L I Q_{1}^{B} \leq e_{1}^{B} \quad\left(\lambda_{1}^{B}\right)
$$

Separately, $B$ decides how to how to allocate the equity and deposits raised by the bank between the risky loan and the liquid asset, i.e.,

$$
I+L I Q_{1} \leq P_{e q}^{B} x_{e q}^{B}+D^{B}+P_{e q}^{B} x_{e q}^{R}+D^{R}+E^{B} \quad\left(\psi_{1}^{B}\right)
$$

It is simpler to separately analyze the cases where the bank-run does and does not occur. If a bank-

\footnotetext{
${ }^{10}$ It is not very surprising that with the kind of market incompleteness that holds in this model that capital structure choices would have consequences for the agents behavior. Financial intermediation helps with the two sources of market incompleteness: uninsurable idiosyncratic risk due to the preference shock in the intermediate period, and uninsurable aggregate risk in the final period due to the fact that there are not enough assets to hedge completely the productivity shocks. The capital structure of the bank would be irrelevant and the Modigliani-Miller result would hold, if aggregation of $R$ and $B$ into one composite saver was possible. In turn, this would imply that both agents price debt, equity and the risky investment the same way, and that they both have HARA utilities with the same risk tolerance given that markers are incomplete (see Rubinstein (1974), Detemple and Gottardi (1998) for a formal analysis). In our calibration we use CRRA utilities for all agents with the same risk-aversion. The reason that Modigliani-Miller fails is that $R$ and $B$ price contracts differently. For example, $R$ cares about early consumption as well as the repayment in the bankruptcy state $3 b$ when he decides how many deposits to hold, while $B$ does not because she is both patient and protected by limited liability, as will be shown in the following section. It is easy to show that for $\delta=0, V_{3 b}^{D}=1, x_{e q}^{R}>0$, and HARA utilities with identical risk tolerance, $R$ and $B$ can be aggregated in a composite saver, and hence the Modigliani-Miller result would hold. A detailed proof is available upon request.
} 
run does not occur at $\mathrm{t}=2$, the bank needs to repay the impatient depositors and decide how much liquidity to transfer to period 3, $L I Q_{2} \cdot{ }^{11}$ So the bank's choice in period 2, assuming that a bank-run does not occur, is ${ }^{12}$

$$
\delta \cdot D^{R}\left(1+r_{2}^{D}\right)+L I Q_{2} \leq L I Q_{1} \quad\left(\psi_{2}^{B}\right)
$$

When there is not a run, $B$ does not withdraw any of her deposits. So in this case all that she decides in the second period is whether to rebalance her portfolio of bank equity and the liquid asset to transfer wealth in the third period, i.e.,

$$
P_{s e c} x_{s e c}^{B}+L I Q_{2}^{B} \leq L I Q_{1}^{B}+P_{s e c} x_{e q}^{B}
$$

The consumption of $B$ in state $3 s$ when the bank survives period 2 is equal her share of banking profits plus her endowments, repayment on her deposits and her liquid holdings, i.e.,

$$
\begin{aligned}
c_{3 s}^{B, \text { no-run }} & \leq \frac{E^{B}+x_{\text {sec }}^{B}}{E^{B}+x_{e q}^{R}+x_{e q}^{B}} \max \left[V_{3 s}^{I} I\left(1+r^{I}\right)+L I Q_{2}-\left((1-\delta) D^{R}+D^{B}\right)\left(1+r_{3}^{D}\right), 0\right] \\
& +V_{3 s}^{D} D^{B}\left(1+r_{3}^{D}\right)+L I Q_{2}^{B}+e_{3 s}^{B} \quad\left(\lambda_{3 s}^{B, n o-r u n}\right)
\end{aligned}
$$

The maximum operator captures the fact that bank shareholders are protected by limited liability and that their other sources of income cannot be seized to repay depositors in bankruptcy. When the value of total assets is lower that the outstanding deposits, the bank is liquidated and the salvage value of the bank is distributed pro-rata to depositors. As a result, the percentage repayment on deposits, which are not withdrawn ealry, is

$$
V_{3 s}^{D}=\min \left[1, \frac{V_{3 s}^{I} I\left(1+r^{I}\right)+L I Q_{2}}{\left((1-\delta) D^{R}+D^{B}\right)\left(1+r_{3}^{D}\right)}\right]
$$

A different set of conditions apply when a bank-run occurs. Recall this can only happen if depositors have rationally determined that the value of the bank's assets are less than promised deposit repayments. In a run the bank liquidates its portfolio and distributes the resulting funds, $L I Q_{1}+\xi \cdot I$, to depositors on a first-come, first-served basis. Hence, each depositor will be repaid in full with probability $\frac{L I Q_{1}+\xi \cdot I}{\left(D^{R}+D^{B}\right)\left(1+r_{2}^{D}\right)}$.

In this scenario $B$ carries over her liquid holding, $L I Q_{1}^{B}$ and any deposit repayment she receives, into the third period and consumes them together with the new endowment, $e_{3 s}^{B}$. If $B$ is lucky, she will receive her deposits in full and her consumption in the third period will be

$$
c_{3 s}^{B, \text { run,paid }} \leq D^{B}\left(1+r_{2}^{D}\right)+L I Q_{1}^{B}+e_{3 s}^{B} \quad\left(\lambda_{3 s}^{B, \text { run,paid }}\right) .
$$

\footnotetext{
${ }^{11}$ The bank could also opt to participate in the secondary market for equity and buyback shares. This could be the case if shares are priced at an attractive enough discount. In particular, an equity buyback requires that $P_{s e c}<P_{e q}^{B}$. But this can never occur in an equilibrium, because $R$ would never invest in equity in the first place (see previous section). Thus, we abstract from this generalization given that it would never occur in equilibrium.

${ }^{12}$ Loans are liquidated at a sufficiently large penalty so it never makes sense to plan to use this source of funding to pay depositors unless there is a run.
} 
Otherwise, she will just consume out of her new endowment and her liquid holdings, i.e.,

$$
c_{3 s}^{B, \text { run,unpaid }} \leq L I Q_{1}^{B}+e_{3 s}^{B} \quad\left(\lambda_{3 s}^{B, \text { run,unpaid }}\right) .
$$

Optimal consumption choices imply that $\lambda_{1}^{B}=U^{B^{\prime}}\left(c_{1}^{B}\right), \lambda_{3 s}^{B, \text { run,paid }}=q \cdot \theta \cdot \omega_{3 s} U^{B^{\prime}}\left(c_{3 s}^{B, \text { run }, \text { paid }}\right)$, $\lambda_{3 s}^{B, \text { run,unpaid }}=q(1-\theta) \omega_{3 s} U^{R^{\prime}}\left(c_{3 s}^{B, \text { run,unpaid }}\right)$ and $\lambda_{3 s}^{B, \text { no-run }}=(1-q) \cdot \omega_{3 s} U^{B^{\prime}}\left(c_{3 s}^{B, \text { no-run }}\right)$.

$\psi_{1}^{B}$ and $\psi_{2}^{B}$ are the Lagrange multipliers for the balance sheet constraints of the bank in the first and second periods (constraints (23) and (24) respectively). From the optimality condition for $L I Q_{1}^{B}$, we obtain that $\psi_{1}^{B}=\psi_{2}^{B}$.

Denote by $s^{D}=\left\{s: V_{3 s}^{D}<1\right\}$ the set of states where the bank defaults. $B$ manages the bank on behalf of the equityholders, so when she optimizes she will ignore states in which the bank defaults and equity is wiped out. The optimality condition for equity raising by $R$, is

$$
\psi_{1}^{B} P_{e q}^{B}-\frac{E^{B}+x_{e q}^{B}}{E^{B}+x_{e q}^{R}+x_{e q}^{B}} \sum_{s \notin s^{D}} \lambda_{3 s}^{B, n o-r u n} D P S_{3 s}=0
$$

where $D P S_{3 s}=\frac{\pi_{3 s}}{E^{B}+x_{e q}^{R}+x_{e q}^{B}}$ are the dividends per share and $\pi_{3 s}=V_{3 s}^{I} I\left(1+r^{I}\right)+L I Q_{2}-V_{3 s}^{D}((1-$

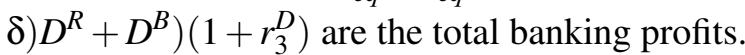

The optimal choices of risky loans' extension and deposit taking, respectively, yield:

$$
\begin{gathered}
-\psi_{1}^{B}+\frac{E^{B}+x_{s e c}^{B}}{E^{B}+x_{e q}^{R}+x_{e q}^{B}} \sum_{s \notin s^{D}} \lambda_{3 s}^{B, n o-r u n} V_{3 s}^{I}\left(1+r^{I}\right)=0, \\
\psi_{1}^{B}\left(1-\delta\left(1+r_{2}^{D}\right)\right)-(1-\delta) \frac{E^{B}+x_{s e c}^{B}}{E^{B}+x_{e q}^{R}+x_{e q}^{B}} \sum_{s \notin s^{D}} \lambda_{3 s}^{B, n o-r u n}\left(1+r_{3}^{D}\right)=0 .
\end{gathered}
$$

Combining conditions (31) and (32), provides several important insights about the way this model works. In particular, these two jointly imply that

$$
\sum_{s \notin s^{D}} \lambda_{3 s}^{B, n o-r u n}\left[V_{3 s}^{I}\left(1+r^{I}\right)-\frac{1-\delta}{1-\delta\left(1+r_{2}^{D}\right)}\left(1+r_{3}^{D}\right)\right]=0,
$$

which says that the expected intermediation spread under limited liability, weighted by the banker's marginal utility, is zero. To better understand this condition, suppose that $r_{2}^{D}=0$. Then, in the two states that the bank cares about, the spread between loans and deposits in state $3 g$ is $r^{I}-r^{D}>0$, while in state $3 m$ it is $V_{3 m}^{I}\left(1+r^{I}\right)-\left(1+r^{D}\right)<0$. So (33) implies that bank takes on sufficient risk and leverage so that it makes losses in the medium risk state of the world. This risk-shifting takes place because the bank ignores the consequences of its investment decision in the bankruptcy state $\left(V_{3 b}^{I}\left(1+r^{I}\right)-\left(1+r^{D}\right)\right)$, which it would have accounted for under unlimited liability (see section 3.2).

While $B$ ignores the bankruptcy state $R$ does not. $R$ recognizes that the excessive risk-taking 
lowers the percentage repayment on deposits in bankrupcty, $V_{3 b}^{D}$. So $R$ will would charge a higher deposit rate (equation (16)) to account for this risk. One critical feature of the model is that the bank does not recognize that $R$ is behaving this way so the limited liability creates a pecuniary externality in the competitive equilibrium. ${ }^{13}$

In addition, the desire of the bank to take more leverage increases the probability of a bankrun. ${ }^{14}$ But notice that $q$ is absent in (33), which means that when the bank risk-shifts it also ignores the impact on the probability of a run. Savers do care about run risk when they decide how much equity and deposits to invest in the bank (equations (16) and (17)), and increases in $q$ reduce their investment in the bank. This is a second externality present in the competitive equilibrium. Section 3.3 discusses how a constrained planner takes this pair of externalities into consideration to make Pareto improving investment and leverage choices.

In selling equity the bank equates the benefits of having more funding in the first period versus the marginal utility of the future dividends that are forgone in period three, weighted by the marginal utility of income in those states of the world where dividends are paid. Substituting equations (31) and (32) into (30), it is easy to see that the price that $B$ is willing to issue equity, $P_{e q}^{B}$, will not be lower than 1 , which is the price of existing equity in the bank. $P_{e q}^{B}>1$ requires that $r_{2}^{D}>0$, otherwise $P_{e q}^{B}=1$. If the price that $R$ is willing to buy equity, $P_{e q}^{R}$, is lower than $P_{e q}^{B}$, then $x_{e q}^{R}=0$ due to the fact that $B$ is not allowed to sell his initial equity holdings, $E^{B}$, or short-sell equity. Otherwise $P_{e q}^{R}=P_{e q}^{B}$ and $x_{e q}^{R}>0$.

Using just these optimality conditions, it is possible to make several observations about the structure of the bank's assets and liabilities that will be useful in our subsequent analysis. The proofs for these claims are given in the appendix, so in the body of the text we merely give the intuition for the findings and explain their significance.

Proposition 1: In period 1, the voluntarily investment of the bank in the liquid asset does not exceed the expected deposit withdrawals in period 2 , i.e., $L I Q_{2}=0$.

This results follows from the limited liability for the bank which drives many of the subsequent results. When $B$ is managing the assets of the bank, she will only consider states that the bank is

\footnotetext{
${ }^{13}$ In other words, the banker is acting like a price-taker who only sees the interest rate that she is forced to offer to attract deposits. The banker is not considering the full supply schedule that the savers contemplate, i.e., she is ignoring the full consumption-savings problem that the savers face. This externality is not present when the prefect competition assumption is dropped. Geanakoplos (1997) proposes a more elaborate market structure such that borrowers account for the "collateral value" of their portfolio on the decision of lenders, while preserving the competitive pricing assumption. He postulates that each lending contract should not only specify the interest rate, but also the resources available to lenders when borrowers default. Then, the supply schedule of each depositor would include a menu of three-dimensional contracts specifying all possible combinations of interest rates, liability structures and asset allocations for the bank, and the bank would then choose the contract that maximizes its objective. This enhanced contract structure can result in constraint efficient allocations in the absence of other externalities (see Geanakoplos and Zame (2013)). It seems plausible to think of such comprehensive contracts in mortgage and bilateral repo markets, but it is hard to conceive of deposit or intermediated lending contracts that are contingent on the whole balance sheet of borrowing institutions (even if such financial innovation may be desirable).

${ }^{14}$ It is easy to see that the bank will not voluntarily issue long-term (LT) debt. Consider that $r_{2}^{D}=0$. Then, the bank would offer $r^{L T}=r_{3}^{D}$ on long-term debt (equation (32)), while savers would require $r^{L T}>r_{3}^{D}$ (equation (16)), because short-term debt carries a liquidity discount. The same holds for $r_{2}^{D}>0$, but the calculations are more complicated.
} 
solvent. Given that in those states, depositors have to be repaid in full at a positive interest rate, the banker will never allocate a marginal unit of funds to an asset that pays a zero return, even though these funds might increase the amount available to the bank's creditors in bankruptcy. This is a general result which holds even when the yield on the riskless asset is positive or allowed to vary endogenously as long it is lower that the deposit rate. Provided this return differential holds then the logic of the of proposition 1 will obtain.

$B$ will choose the minimum interest rate offered to depositors who withdraw early, $r_{2}^{D}$. The bank opts for the lowest deposit rate, $r_{2}^{D}$ because the amount of liquidity that the bank needs to hold from period 1 to period 2 is increasing in $r_{2}^{D}$ other things equal. Given that the liquid asset is dominated by the risky loan in net present value terms, the bank will choose to hold the minimum liquidity necessary since it disregards any other general equilibrium effects that higher liquid asset holding bring along.

Moreover, the equilibrium long-term deposit rate, $r_{3}^{D}$, should be high enough such that patient depositors have an incentive to keep their deposits in the bank as long as long as they expect that other patient depositors will act the same way. The incentive compatibility constraint such that patient households do not withdraw early in normal times has to account for the possibility of trading in the secondary equity market after withdrawing (see Fahri et al. (2009) for a DiamondDybvig model with hidden trades). The consumption of a patient depositors who waits given that all other depositors also wait is given by equation (13). On the other hand, if he withdraws early he can consume $x_{\text {sec }}^{R^{\prime}}\left(D P S_{3 s}-P_{\text {sec }}\right)+D^{R}\left(1+r_{2}^{D}\right)+L I Q_{1}^{R}+P_{\text {sec }} x_{e q}^{R}+e_{2}^{R}$, where $x_{\text {sec }}^{R^{\prime}}$ is the number of equity shares he purchases in the secondary equity market, and is different from the number of shares, $x_{s e c}^{R}$, that depositors who do not withdraw early purchase. The optimal $x_{s e c}^{R^{\prime}}$ is given by

$$
P_{s e c}=\frac{\sum_{s} \omega_{3 s} U^{R}\left(x_{s e c}^{R^{\prime}}\left(D P S_{3 s}-P_{s e c}\right)+D^{R}\left(1+r_{2}^{D}\right)+L I Q_{1}^{R}+P_{s e c} x_{e q}^{R}+e_{2}^{R}\right) D P S_{3 s}}{\sum_{s} \omega_{3 s} U^{R}\left(x_{s e c}^{R^{\prime}}\left(D P S_{3 s}-P_{s e c}\right)+D^{R}\left(1+r_{2}^{D}\right)+L I Q_{1}^{R}+P_{s e c} x_{e q}^{R}+e_{2}^{R}\right)},
$$

where $P_{s e c}$ is given by combining equations (19) and (20). Then, patient depositors will prefer to wait if

$$
\begin{aligned}
& \sum_{s} \omega_{3 s} U^{R}\left(x_{s e c}^{R}\left(D P S_{3 s}-P_{s e c}\right)+V_{3 s}^{D} D^{R}\left(1+r_{3}^{D}\right)+L I Q_{1}^{R}+P_{s e c} x_{e q}^{R}+e_{2}^{R}\right) \geq \\
& \sum_{s} \omega_{3 s} U^{R}\left(x_{s e c}^{R^{\prime}}\left(D P S_{3 s}-P_{s e c}\right)+D^{R}\left(1+r_{2}^{D}\right)+L I Q_{1}^{R}+P_{s e c} x_{e q}^{R}+e_{2}^{R}\right)
\end{aligned}
$$

(35) simply says that the total expected utility that a patient household obtains by waiting is higher that the utility from withdrawing early given than only impatient household withdraw and all other patient ones wait, and it should hold for both $x_{\text {sec }}^{R^{\prime}}=0$ and $x_{\text {sec }}^{R^{\prime}}>0$ (given by (34)) since a patient depositor who withdraws early can opt to trade in the secondary market or not. In the calibrations we consider, (35) will be satisfied for $r_{2}^{D}=0$.

It is also possible to be more specific about the way that the bank will be funded. First, we outline conditions under which $B$ will not invest any of her period 1 endowment in bank deposits 
or the liquid asset. $B$ does not hold deposits in the bank (i.e., $D^{B}=0$ ) or invest in the liquid asset $\left(L I Q_{1}^{B}=0\right)$, if the following conditions hold, respectively, in equilibrium:

$$
\begin{gathered}
-U^{B^{\prime}}\left(e_{1}^{B}\right)+(1-q) \sum_{s} \omega_{3 s} U^{B^{\prime}}\left(c_{3 s}^{B, n o-r u n}\right) V_{3 s}^{D}\left(1+r_{3}^{D}\right)+q \cdot \theta \cdot \sum_{s} \omega_{3 s} U^{B^{\prime}}\left(e_{3 s}^{B}\right)\left(1+r_{2}^{D}\right)<0 \\
-U^{B^{\prime}}\left(e_{1}^{B}\right)+(1-q) \sum_{s} \omega_{3 s} U^{B^{\prime}}\left(c_{3 s}^{B, n o-r u n}\right)+q \sum_{s} \omega_{3 s} U^{B^{\prime}}\left(e_{3 s}^{B}\right)<0
\end{gathered}
$$

The decision to invest in the liquid asset is akin to the decision that $\mathrm{R}$ makes. Incrementally investing in the safe asset reduces first period consumption and then transfers resources to the second period which will support future consumption (which will differ depending on whether or not a run occurs). A more precise statement can be made about whether B will invest more of her endowment in bank equity.

Proposition 2: If the bank defaults in any state of the world, then B will not devote any of her endowment to investing in equity in the bank, i.e., $x_{e q}^{B}=0$.

This reluctance of $B$ to provide more equity comes because the bank only has a debt contract with the entrepreneur. So when the entrepreneur's project fails, $B$ is already at risk for suffering losses before any depositors are paid, but when the project succeeds the upside gains to $B$ are capped by the interest payment. So if $B$ were to invest in more equity, doing so would add more losses in states of nature when $B$ already has low consumption in exchange for additional consumption in other states where consumption would already be higher.

In contrast, for $R$ there potentially are gains to providing some funding through both debt and equity. The advantage of debt funding is that it is partly protected in cases where $P$ defaults on the loan. The motivation to provide some equity funding is that the bank is already charging $P$ more for the loan than it is paying on its deposits. By buying some equity in the bank, $R$ partially shares in the profits from intermediation. By this same logic, $B$ might be interested in depositing some of her endowment in the bank in order to partially hedge against the default risk of $P$. Hence, because we will always consider environments where default can occur the feasible equilibria to be studied can possibly involve an equity investment in the bank by $R$ and deposits by either $R$ and/or $B$.

Finally, the condition that clears the secondary market for equity is

$$
x_{e q}^{R}=(1-\delta) x_{s e c}^{R}
$$

The total supply of banking shares is $x_{e q}^{R}$ since both impatient and patient savers offer their shares for sale. However, only a fraction of $1-\delta$ savers purchase stocks in addition to any shares that the bank buys back and cancels. 


\section{Benchmarks}

Before we examine how regulation can affect economic outcomes, we first solve for calibrated version of the competitive economy and contrast it to two alternatives. The first is one where borrowers are not protected by limited liability. With unlimited liability the total amount that can borrowed is capped by agents endowments in the bad states of the world where the project fails. These natural debt limits result in lower credit extension and provide a useful benchmark that can be contrasted to competitive equilibrium. The second comparison is to the equilibrium selected by a constrained social planner who internalizes everything and can choose allocations directly. In this second benchmark, the planner respects the pricing of contracts in the competitive equilibrium and can only use the existing assets to reallocate resources across agents.

\subsection{Calibrated competitive equilibrium}

The full set of parameters we used to solve the model and the equilibrium outcomes are shown in the appendix in Tables 18 and 19, respectively. Let us just call attention to five of the considerations that we took into account in choosing these parameters.

First, the probablities of default and losses given default will determine the amount of default risk that $B$ is being facing. The baseline calibration supposes that $P$ defaults in both the medium and bad state, but that there is enough bank equity so that depositors only suffer losses in the bad state.

Some of the other parameters in this simulation, such as the coefficient of relative risk aversion (set to 2.1 for each agent)for a CRRA utility and the share of income for the risky technology accruing to the entrepreneur (set to 0.3 ) are chosen to match standard estimates from the literature. ${ }^{15}$ Though others such as the level of the endowments, the probabilities of default, and losses given default, are hard to judge in isolation. Collectively these parameters do influence the level of capital in the bank, so these were chosen so that in this example the (endogenous) capital ratio would be around $15 \%$.

Overall, this parameterization should be taken more as an illustrative example than a realistic calibration of the economy. We have experimented with various other parameter choices and the findings are very robust. The robustness is not surprising because the model is still simple enough so that the main driving forces behind the most important results are easy to understand.

Second, the spread between the deposit rate and the lending rate is large enough that $R$ finds it appealing to invest a small amount of his endowment in equity in the bank. But most of $R^{\prime} s$ savings are in the form of deposits. In this example, $B$ opts not to make any deposits in the bank, though we have explored other parameterizations in which $B$ does make deposits and nothing that we emphasize in what follows depends on whether $B$ does or does not make a deposit.

\footnotetext{
${ }^{15}$ Gollin (2005) finds that the share of profits in entrepreneurial activities is 0.10 . The rest is the share of labor and capital. In our setting, labor from workers is not modeled, and we are interested in the share of the remaining output which is distributed to entrepreneurs and supplier of capital. Setting the share of capital relatively to labor to 0.30 , which is standard in the literature, give a relative share for entrepreneurial and capital profits of $0.1 /(0.1+0.9 \cdot 0.3)=0.28$ and $(0.9 \cdot 0.3) /(0.1+0.9 \cdot 0.3)=0.72$, respectively.
} 
Third, the liquidation value, $\xi$, of long-term investment is such that the probability that a depositor will be fully repaid if a bank run occurs is $\theta=0.67$. This sets the probability of a bank run at around $11 \%$. Except in a run, the patient households never choose to withdraw early.

Fourth, the lending rate is attractive enough for $P$ to borrow substantially. One way to assess the level of borrowing is to compare it to the total endowment that is available in period 1. Judged that way, investment accounts for about $21 \%$ of total first period resources. The other way, which perhaps is more informative about the preference of $P$ to gamble by exploiting limited liability is to note that investment exceeds $P^{\prime} s$ third period endowment by a factor of nearly three.

Fifth, expected volatility of consumption for the entrepreneur is substantial. Of course, this depends mostly on the endowments but the endogenous investment choices also matter and because of the high level of investment, $P^{\prime} s$ consumption is about 2.9 times more in the good state than in medium and 7.26 times than in the bad state, even though endowments are the same in the good and medium state, and only 2.4 times higher than in the bad state. $R^{\prime} s$ consumption is also substantially more volatile in the second period than are his endowments.

Table 1: Main variables

\begin{tabular}{|c|c|c|c|c|c|}
\hline$V_{2 g}^{I}=1.00$ & $V_{2 g}^{D}=1.00$ & $C R=14.77 \%$ & $\frac{I}{\sum e_{1}}=21 \%$ & $\frac{c_{3 g}^{P, n o-r u n}}{c_{3 m}^{P, n o-r u n}}=2.91$ & $\frac{c_{3 g}^{R, p, n o-r u n}}{c_{3 m}^{R, p, n o-r u n}}=1.06$ \\
\hline$V_{2 m}^{I}=0.82$ & $V_{2 m}^{D}=1$ & $L R=21.31 \%$ & $\frac{I}{e_{3 g}^{P}}=2.55$ & $\frac{c_{3 g}^{P, n o-r u n}}{c_{3 b}^{P, n o-r u n}}=7.26$ & $\frac{c_{3 g}^{R, p, n o-r u n}}{c_{3 b}^{R, p, n o-r u n}}=1.80$ \\
\hline$V_{2 b}^{I}=0.17$ & $V_{2 b}^{D}=0.23$ & $q=10.93 \%$ & $\frac{I}{e_{3 b}^{P}}=6.37$ & $r^{I}-r^{D}=17.46 \%$ & $\frac{\mathbb{E}\left(c_{3 s}^{R, p, n o-r u n}\right)}{c_{2}^{R, i, n o-r u n}}=1.19$ \\
\hline
\end{tabular}

\subsection{Unlimited liability}

To better understand the competitive calibration consider how things change when agents are subject to unlimited liability. We present this alternative to clarify the importance of the limited liability which we have seen leads to excessive risk-taking. Table 19 presents the full set of outcomes.

When default is not permitted then all lending contracts will be constrained by the endowments of the entrepreneur and the bank, so that there is always enough collateral that can be seized to insure that deposits and loans are fully repaid. ${ }^{16}$ This restriction, therefore, naturally reduces lending which in turn significantly reduces $P^{\prime} s$ welfare since the profitability of the project in the good state is forgone. The size of this effect depends on $P^{\prime} s$ endowments in the bad state because in this state output from the risky investment is not high enough to cover the loan obligation. So the size of that endowment determines the natural borrowing limit that $P$ will face.

\footnotetext{
${ }^{16}$ This requires that all of the future endowments/income of agents can be collateralized.
} 
Curtailing the ability of $P$ to take loans, reduces the size of the bank's balance sheet and consequently its leverage. In this calibration, the liquidation value of the bank's assets over total deposits is higher than one $\left(\frac{L I Q_{1}+\xi \cdot I}{D^{R}\left(1+r_{2}^{D}\right)}=1.34\right)$, and the probability of a bank-run is zero. ${ }^{17}$

The option to default is valuable for $\mathrm{B}$, because she can take advantage of higher profits when the project succeeds while protecting her wealth in the bad state from being seized. Under unlimited liability the spread between borrowing and lending drops to zero, because both deposits and loans will be risk-free. In principle, $\mathrm{R}$ could be better or worse off. On one hand, eliminating default helps him. On the other hand, the return on savings is lower and $R$ can hedge less effectively, since he can invest only in a risk-free asset instead of acquiring both deposits and equity. We find that risky investment drops by $87.93 \%$ and all agents are worse-off compared to the economy with limited liability. $P^{\prime} s$ utility drops by $1.15 \%, R^{\prime} s$ by $3.84 \%$ and $B^{\prime} s$ by $1.02 \% .^{18}$

\subsection{Constrained social planner}

As a second point of comparison we solve for the allocations that a social planner will choose. We require the planner's allocations to be incentive compatible for each agent. ${ }^{19}$ This means that the planner recognizes the distorting effects of limited liability and internalizes the social inefficiency of a run, but combats these problems using existing traded contracts. Also, the pricing of these contracts remains consistent with the payoffs that they deliver to the agents as in the competitive equilibrium. Finally, the planner respects the incentive compatibility constraint (35), which means that the planner cannot choose very low deposit rates because depositors' types are private information and patient depositors may prefer to withdraw early. ${ }^{20}$

Given market incompleteness, we cannot unambiguously construct a social welfare function. Thus, we assign weights for different agents in a social welfare function (and study different constellations of these weights). In the comparisons with different weights, we want to make sure that the baseline level of utilities of the agents are similar; for instance, if $B^{\prime} s$ base level of utility is much different than the other agents, then transfers between $B$ and the other agents will mechan-

\footnotetext{
${ }^{17}$ Bank-runs are, in principle, possible even with unlimited liability as in Diamond-Dybvig. The initial banking capital $E^{B}$ in our model protects depositors against early liquidation when the bank has a small balance sheet.

${ }^{18}$ Market incompleteness and limited risk-sharing renders the default option valuable for agents, because it expands the set of assets they can trade. See Dubey et al. (2005) and Zame (1993) for a proof that default can be welfare improving when assets markets are incomplete.

${ }^{19}$ The planner also respects the short-sales constraints for equity holdings $\left(I^{P}, x_{e q}^{R}, x_{e q}^{B} \geq 0\right)$, deposits $\left(D^{R}, D^{B} \geq 0\right)$, and liquid holdings by all agents, as well as the nature of the demand deposit contract which stipulates that $r_{2}^{D}, r_{3}^{D} \geq 0$.

${ }^{20} \mathrm{We}$ assume that the planner cannot restrict depositors who withdraw early from trading in the secondary market for equity. Thus, the planner needs to account for the fact that agents may engage in hidden trades. Given the allocations that the planner chooses, the effective equity price in the secondary market is given by the resources transferred to the impatient depositors who "sell" their total equity holdings to the patient ones, i.e., $P_{s e c}=\frac{1-\delta}{\delta} \frac{e_{2}^{R}-L I Q_{2}^{s p}}{x_{e q}^{R}}$. Finally, the planner can influence the decision of agents to purchase equity in the secondary market, i.e. the planner can introduce a wedge in the optimality conditions (19), (20) and (34). These jointly determine the level of "out-of-equilibrium" hidden trades, which is an input in the incentive compatibility constraint (35) faced by the planner. In section, 4.2 we present specific tools that can be used to implement the planner's solution when the incentive compatibility constraint in the presence of hidden trades is binding.
} 
ically generate changes in the aggregate, weighted average level of utility. To eliminate this issue we normalize agents' utilities by the (indirect) utility they obtain in the competitive equilibrium denoted by $\bar{V}^{\text {c.e. }}$. We take the absolute value because the equilibrium value of utilities is negative. ${ }^{21}$ The social welfare function we consider, with weights $w^{P}, w^{R}$ and $w^{B}$, which are positive and sum up to 1 , is:

$$
\bar{U}^{s p}=w^{P} \frac{\bar{U}^{P}}{\left|\bar{V}^{P, c . e .}\right|}+w^{R} \frac{\bar{U}^{R}}{\mid \bar{V}^{\text {R.c.e. } \mid}}+w^{B} \frac{\bar{U}^{B}}{\left|\bar{V}^{B, c . e .}\right|}
$$

where $\bar{U}^{P}, \bar{U}^{R}$ and $\bar{U}^{B}$ are given by equations (2), (9) and (21), respectively.

We proceed by constructing the budget constraints for the social planner. In the calibration of the competitive equilibrium $B$ does not invest in bank equity, deposits or the liquid asset, and $P$ does not invest any of his initial endowment in the risky project, and the bank sets $r_{2}^{D}=0$. For simplicity, the planner's budget constraints that follow presume that these properties will be true, but we verify that this is the case in equilibrium. ${ }^{22}$ Thus, the planner faces the following period 1 budget/resource constraint, which is derived by combining constraints (3), (10), (22), and (23):

$$
c_{1}^{P}+c_{1}^{R}+c_{1}^{B}+I^{s p}+L I Q_{1}^{s p} \leq e_{1}^{P}+e_{1}^{R}+e_{1}^{B}+E^{B},
$$

where $c_{P}^{1} \leq e_{1}^{P}$ and $c_{B}^{1} \leq e_{1}^{B}$. Constraint (40) says that the planner allocates all available resources in period 1 to current consumption and investment by the bank in the liquid and risky technologies. The way that the future payoffs from these investments are allocated to agents is constrained by the underlying assets the planner is obliged to use. The implicit deposit and equity holdings to $R$ are given by $D^{R}=\frac{L I Q_{1}^{s p}(1-\phi)}{\delta}$ and $x_{e q}^{R}=I^{s p}-\frac{1-\delta-\phi}{\delta} L I Q_{1}^{s p}-E^{B}$, respectively. ${ }^{23}$

Since $B$ has no deposits, the resource constraint of the planner in period 2 in the event of a run comes from combining equations (14) and (15):

$$
c_{2}^{R, \text { run }, \text { paid }} \cdot \delta \frac{L I Q_{1}^{s p}+\xi \cdot I^{s p}}{L I Q_{1}^{s p}(1-\phi)}+c_{2}^{R, \text { run }, \text { unpaid }} \cdot\left(1-\delta \frac{L I Q_{1}^{s p}+\xi \cdot I^{s p}}{L I Q_{1}^{s p}(1-\phi)}\right) \leq L I Q_{1}^{s p}+\xi \cdot I^{s p}+e_{2}^{R} .
$$

where $c_{2}^{R, \text { run,unpaid }} \leq e_{2}^{R}$. Constraint (41) says if there is a bank-run, the planner liquidates the bank's loans, and uses the proceeds along with the liquid assets and the available endowment in period 2 to pay off depositors in a first-come, first-first served fashion. Some depositors will be repaid their deposits in full, while the rest receive nothing and must consume their new endowment.

If a bank run is avoided, equations (11), (12), combined with the equity market clearing condi-

\footnotetext{
${ }^{21}$ We could have adjusted the intercepts in the agents' original utility functions to essentially do the same thing. All that matters is setting the baseline levels of utility so that marginal transfers do not automatically create first-order changes purely because of a failure to normalize properly.

${ }^{22}$ These non-negativity and short-selling constraints are binding in the competitive equilibrium. So the individual agents would have preferred to violate these constraints. Hence, we forbid the planner from achieving gains by violating the constraints.

${ }^{23}$ The implicit level of deposits is derived using constraint (24) and denoting by $\phi \cdot L I Q_{1}^{s p}$ the liquid holdings $\left(L I Q_{2}\right)$ that the bank transfers from period 2 to period 3 , where $\phi \in[0,1]$. The implicit level of equity is derived from constraint (23) using the fact that the pricing of equity in the competitive equilibrium yields $P_{e q}^{B}=1$.
} 
tion, (38), give the period 2 resource constraint of the planner:

$$
\delta \cdot c_{2}^{R, i, n o-r u n}+\phi \cdot L I Q_{1}^{s p}+(1-\delta) L I Q_{2}^{s p} \leq L I Q_{1}^{s p}+e_{2}^{R}
$$

Constraint (42) says that the planner has liquid assets from the first period plus the second period endowment available to distribute. These resources must be divided between repaying deposits, funding consumption by the impatient households and reinvesting in the liquid asset to support subsequent consumption. Total investment in safe assets consists of the amount of liquid assets held by the bank from period 2 to period $3, \phi \cdot L I Q_{1}^{s p}$, and the liquid holding of all patient households, $L I Q_{2}^{s p}$.

The resource constraints in state $s$ in period 3 when a bank run does not occur are:

$$
(1-\delta) \cdot c_{3 s}^{R, p, n o-r u n}+c_{3 s}^{B, n o-r u n}+c_{3 s}^{P, n o-r u n} \leq A_{3 s} \cdot\left(I^{s p}\right)^{a}+\phi L I Q_{1}^{s p}+(1-\delta) L I Q_{2}^{s p}+e_{3 s}^{B}+e_{3 s}^{P} .
$$

The constraints say that the total payoff from the risky investment, the liquid holdings in the bank and the liquid assets held by patient households plus the new endowments are distributed to patient households, entrepreneurs and bankers for consumption.

Using the fact that investment was optimally chosen so that $1+r^{I}=a \cdot A_{2 g} \cdot I^{a}$ and that $D^{R}=$ $\frac{L I Q_{1}(1-\phi)}{\delta}$, and setting $\eta=\frac{x_{e q}^{R}}{E^{B}+x_{e q}^{R}}, R^{\prime} s$ consumption is states $3 g, 3 m$ and $3 b$ is given by:

$$
\begin{gathered}
c_{3 g}^{R, p, n o-r u n} \leq \frac{1}{1-\delta} \cdot \eta \cdot\left(a \cdot A_{3 g} \cdot\left(I^{s p}\right)^{a}+\phi L I Q_{1}^{s p}\right)+\frac{1}{\delta}(1-\eta) \cdot(1-\phi) L I Q_{1}^{s p}\left(1+r_{3}^{D}\right)+L I Q_{2}^{s p} \\
c_{3 m}^{R, p, n o-r u n} \leq \frac{1}{1-\delta} \cdot \eta \cdot\left(A_{3 m} \cdot\left(I^{s p}\right)^{a}+\phi L I Q_{1}^{s p}\right)+\frac{1}{\delta}(1-\eta) \cdot(1-\phi) L I Q_{1}^{s p}\left(1+r_{3}^{D}\right)+L I Q_{2}^{s p} \\
c_{3 b}^{R, p, n o-r u n} \leq \frac{1}{1-\delta} \cdot\left(A_{3 b} \cdot\left(I^{s p}\right)^{a}+\phi L I Q_{1}^{s p}\right)+L I Q_{2}^{s p} .
\end{gathered}
$$

Constraints (44), (45) and (46) say that the aggregate consumption of patient households given that the bank survives $\left((1-\delta) c_{3 s}^{R, p, n o-r u n}\right)$ is equal to their share of banking profits $(\eta)$ plus the repayment on outstanding deposits and the liquidity carried over from period 2. Banking profits are equal to the return on risky investment and the liquid banking holdings carried over from period 2 minus deposit repayment. In state $3 g$ the entrepreneur fully repays his loan and the bank receives a fraction $a$ of the total output, while in state $3 m$ he defaults and the bank receives the all the output (which was pledged as collateral). In both cases, deposits are repaid in full. In state $3 b$ both the bank and the entrepreneur default and depositors receive the salvage value of the risky investment and the remaining liquidity held by the bank. ${ }^{24}$

\footnotetext{
${ }^{24}$ The planner respects the incentives of private agents in choosing whether to default. Thus, the planner will default on the loan when total output is less that the promised repayment and will default on deposits when the salvage value of the bank is less than the outstanding deposits.
} 
The planner recognizes the balance sheet constraint that implies:

$$
\eta=\frac{I^{s p}-\frac{1-\delta-\phi}{\delta} L I Q_{1}^{s p}-E^{B}}{I^{s p}-\frac{1-\delta-\phi}{\delta} L I Q_{1}^{s p}}
$$

and, in addition, respects the pricing of $r_{3}^{D}$ in the competitive solution, given by:

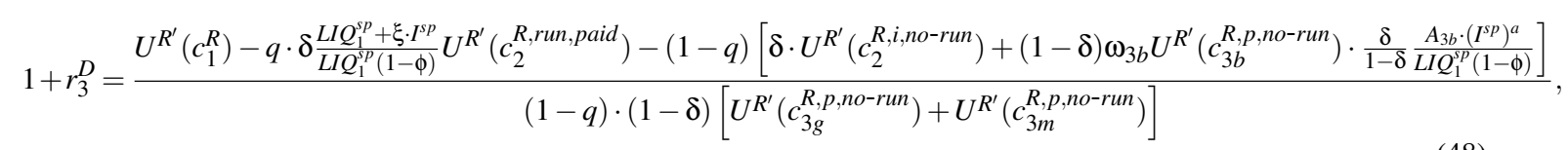

which is derived from equation (16) after substituting the probability that depositors are served in a bank-run and equations (7), (27).

Importantly, the planner internalizes the effect of the investment decisions on the probability of a bank run, and thus accounts for the fact that

$$
q=\left(1-\delta \frac{L I Q_{1}^{s p}+\xi \cdot I^{s p}}{L I Q_{1}^{s p}(1-\phi)}\right)^{2}
$$

or $q=0$ if $\delta \frac{L I Q_{1}^{s p}+\xi \cdot I^{s p}}{L I Q_{1}^{s p}(1-\phi)} \geq 1$.

$P^{\prime} s$ consumption in state $3 g$ given that a bank run does not occur is

$$
c_{3 g}^{P, \text { no-run }} \leq(1-a) \cdot A_{3 g} \cdot\left(I^{s p}\right)^{a}+e_{3 g}^{P}
$$

Finally, the following constraints are (trivially) satisfied

$$
c_{3 m}^{P, \text { no-run }} \leq e_{3 m}^{P}, \quad c_{3 b}^{P, \text { no-run }} \leq e_{3 b}^{P}, \quad c_{3 s}^{P, r u n} \leq e_{3 s}^{P}, \quad c_{3 s}^{B, \text { run }} \leq e_{3 s}^{B}
$$

The planner chooses $\left(c_{1}^{P}, c_{3 s}^{P, \text { no-run }}, c_{3 s}^{P, r u n}\right),\left(c_{1}^{R}, c_{2}^{R, i, n o-r u n}, c_{2}^{R, \text { run,paid }}, c_{2}^{R, \text { run }, \text { unpaid }}, c_{3 s}^{R, p, \text { no-run }}\right)$, $\left(c_{1}^{B}, c_{3 s}^{B, n o-r u n}, c_{3 s}^{B, r u n}\right), I^{s p}, L I Q_{1}^{s p}, L I Q_{2}^{s p}, \eta, r_{3}^{D}, q$ to maximize (39) subject to constraints (40)-(51).

The planner wrestles with two considerations. On the one hand, it is desirable to reduce the risk of the run. On the other hand, the planner tries to mitigate the problems arising from excessive risktaking. Table (2) shows regardless of the weights on the different agents, the planner can always achieve higher overall social welfare than the competitive economy. It is helpful to distinguish three responses from the planner to alleviate the two externalities. First, the planner can choose higher liquidity ratios and (much) lower investment than the competitive equilibrium. These cases are indicated by purple shading in the table. Second, the planner can choose higher capital ratios and lower investment (as indicated by the blue shaded region). Third, the planner can choose higher capital ratios and higher investment than the competitive solution (the green region). The planner's best response depends on the weights assigned to the three types of agents in the social welfare function. In other words, the planner will correct for the bank-run and risk-taking externalities 
differently depending on which of the agents are favored.

In our analysis we will consider all possible potential Pareto weights. Taken literally, one might decide that the bankers per se should be given little weight in the objective function, since they constitute such a small percentage of the population (and wealth distribution). But, given their political clout in regulatory questions, we think it is instructive to see which kind of outcomes would emerge if the planner behaves as if the bankers have a disproportionately high weight.

Table 2: \% Change in Social Welfare: Constrained Planner vs. Competitive Equilibrium

\begin{tabular}{|c|c|c|c|c|c|c|c|c|c|}
\hline & \multicolumn{8}{|c|}{$w^{R}$} \\
\hline & & 0.100 & 0.200 & 0.300 & 0.400 & 0.500 & 0.600 & 0.700 & 0.800 \\
\hline \multirow{8}{*}{$w^{P}$} & 0.100 & $6.77 \%$ & $5.43 \%$ & $4.10 \%$ & $2.77 \%$ & $2.05 \%$ & $2.08 \%$ & $2.13 \%$ & $2.21 \%$ \\
\hline & 0.200 & $5.79 \%$ & $4.44 \%$ & $3.10 \%$ & $2.02 \%$ & $2.05 \%$ & $2.10 \%$ & $2.19 \%$ & - \\
\hline & 0.300 & $4.82 \%$ & $3.47 \%$ & $2.12 \%$ & $2.02 \%$ & $2.07 \%$ & $2.18 \%$ & - & - \\
\hline & 0.400 & $3.86 \%$ & $2.51 \%$ & $1.99 \%$ & $2.05 \%$ & $2.17 \%$ & - & - & - \\
\hline & 0.500 & $2.92 \%$ & $1.95 \%$ & $2.03 \%$ & $2.17 \%$ & - & - & - & - \\
\hline & 0.600 & $1.92 \%$ & $2.01 \%$ & $2.18 \%$ & - & - & - & - & - \\
\hline & 0.700 & $2.01 \%$ & $2.22 \%$ & - & - & - & - & - & - \\
\hline & 0.800 & $2.31 \%$ & - & - & - & - & - & - & - \\
\hline
\end{tabular}

To understand the intuition for these findings, notice two things about the structure of the model. First, a run is welfare-reducing for all three agents: some savers lose their deposits, the entrepreneurs have their loans pulled, and the bank (and the saver) see their equity wiped out. So the planner can make everyone better off by driving down the probability of a run. Table (3) shows the change in the probability of a bank-run between the competitive equilibrium and the planner's solution. No matter who the planner cares most about most, it is always desirable to reduce the likelihood of a run.

Table 3: Percentage points difference in the probability of a bank-run: Constrained Planner vs. Competitive Equilibrium

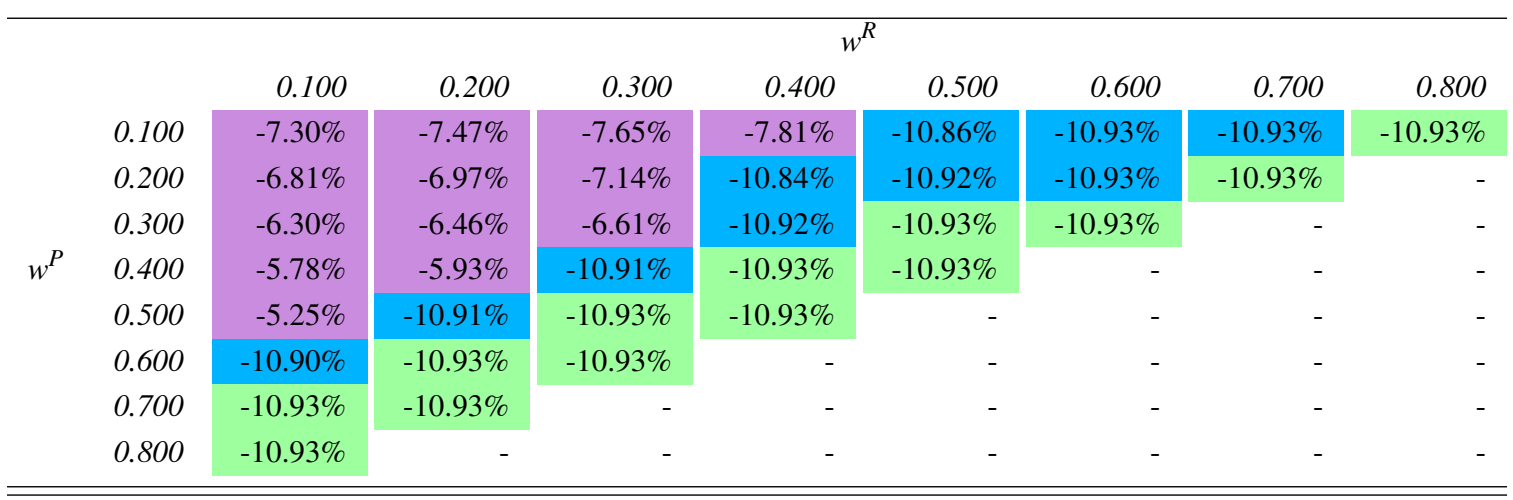

Second, there two ways of reducing the risk of the run. The bank can be made to hold more safe assets and do less lending, or it can be forced to increase equity financing and rely less on deposit 
financing. Either of these actions make deposits safer, but the endogenous response by the agents will differ markedly and the allocational impact will also be quite different. Tables 4 and 5 show the change in capital and liquidity ratios compared to the competitive equilibrium,

Table 4: Percentage points difference in Capital Ratios: Constrained Planner vs. Competitive Equilibrium

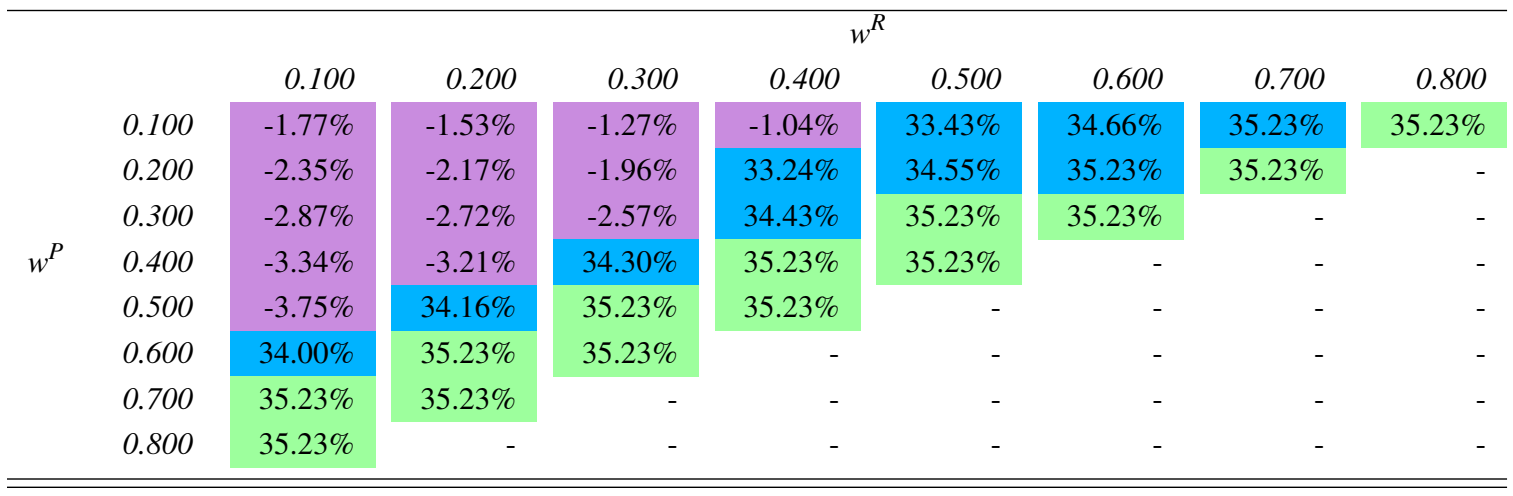

Table 5: Percentage points difference in Liquidity Ratios: Constrained Planner vs. Competitive Equilibrium

\begin{tabular}{|c|c|c|c|c|c|c|c|c|c|}
\hline & & & & & & & & & \\
\hline & & 0.100 & 0.200 & 0.300 & 0.400 & 0.500 & 0.600 & 0.700 & 0.800 \\
\hline & 0.100 & $85.66 \%$ & $89.42 \%$ & $93.70 \%$ & $97.64 \%$ & $-8.36 \%$ & $-8.66 \%$ & $-8.81 \%$ & $-8.81 \%$ \\
\hline & 0.200 & $76.10 \%$ & $79.12 \%$ & $82.47 \%$ & $-8.31 \%$ & $-8.64 \%$ & $-8.81 \%$ & $-8.81 \%$ & - \\
\hline & 0.300 & $67.60 \%$ & $70.07 \%$ & $72.65 \%$ & $-8.61 \%$ & $-8.81 \%$ & $-8.81 \%$ & - & - \\
\hline$w^{P}$ & 0.400 & $60.00 \%$ & $62.06 \%$ & $-8.58 \%$ & $-8.81 \%$ & $-8.81 \%$ & - & - & - \\
\hline & 0.500 & $53.18 \%$ & $-8.54 \%$ & $-8.81 \%$ & $-8.81 \%$ & - & - & - & - \\
\hline & 0.600 & $-8.50 \%$ & $-8.81 \%$ & $-8.81 \%$ & - & - & - & - & - \\
\hline & 0.700 & $-8.81 \%$ & $-8.81 \%$ & - & - & - & - & - & - \\
\hline & 0.800 & $-8.81 \%$ & - & - & - & - & - & - & - \\
\hline
\end{tabular}

Consider first the scenarios in which the planner compels the bank to reduce deposit finance and increase equity financing. This directly reduces the option value that bank gets from potentially defaulting on its deposits. So if the planner cares a lot about the banker, as in the upper left portion of the Tables, this not the best way to deal with the run. So this consideration explains why in Tables 4 and 5 and the planner lowers capital ratios and raises liquid asset holdings when the banker is relatively important.

When the banker is relatively less important, the planner pushes the bank to use more equity financing. This approach reduces bank's ability to exploit limited liability. However, from Table 3 , we see that the planner will almost eliminate the run and by eliminating that risk the bank is typically still better off than in the competitive equilibrium. The other two agents clearly prefer this 
way of controlling the run. For $R$ this approach gives him a higher return on savings. $P$ is not nearly as constrained as when liquidity regulation is aggressively deployed.

The planner is also aware of the perverse incentives created by limited liability and resulting distortions in interest rates. Table 6 shows the change in investment as determined by the planner compared to the competitive equilibrium. The gambling by the bank and entrepreneur in most cases leads to more investment than the social planner prefers.

Table 6: \% Change in Investment: Constrained Planner vs. Competitive Equilibrium

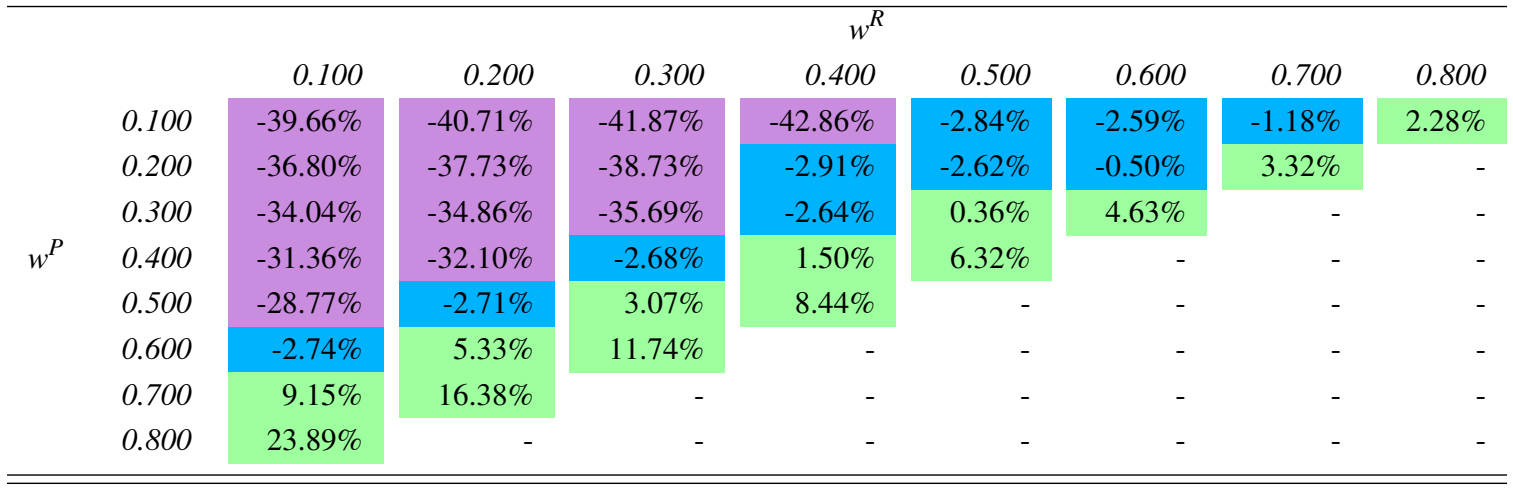

The exceptions to this general pattern happen for two reasons. If the planner is sufficiently concerned with $P^{\prime} s$ welfare, as in the lower left portion of the table, then the planner wants to allow $P$ to invest more. Table 7 shows change the intermediation spread, $r^{I}-r^{D}$, and notice that when the weight on $P$ is sufficiently high, the planner will make the spread negative. This is a way to transfer resources to $R$ and $P$ at the expense of $B$. We consider these cases sufficiently implausible that we exclude them from consideration in our subsequent discussion of optimal regulation.

Table 7: Percentage points difference in Intermediation Spread: Constrained Planner vs. Competitive Equilibrium

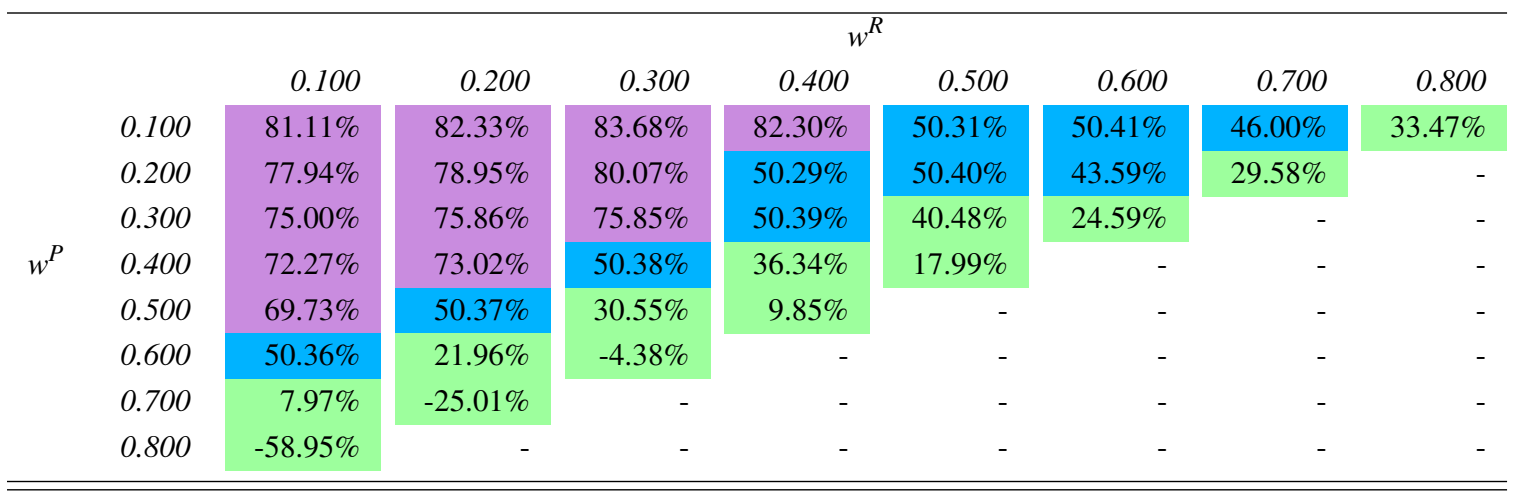

The other cases where the planner compels extra investment occur for a more subtle reason. Consider the upper right portion of the Table 6 . In this region, planner puts relatively little weight on both the entrepreneur and the bank. In the green shaded areas investment also rises. In these 
cases, capital has been increased sufficiently to drive the risk of a run to zero. At this point, there are two ways left to keep helping $R$. One is raise deposit rates. Table 8 shows that is one thing that happens. The other is to raise investment to improve dividend payouts that $R$ also partially receives.

Table 8: Deposit Rate in Planner's solution

\begin{tabular}{|c|c|c|c|c|c|c|c|c|c|}
\hline & \multicolumn{8}{|c|}{$w^{R}$} \\
\hline & & 0.100 & 0.200 & 0.300 & 0.400 & 0.500 & 0.600 & 0.700 & 0.800 \\
\hline \multirow{8}{*}{$w^{P}$} & 0.100 & 0.05 & 0.04 & 0.04 & 0.07 & 0.08 & 0.08 & 0.12 & 0.22 \\
\hline & 0.200 & 0.05 & 0.05 & 0.05 & 0.08 & 0.08 & 0.14 & 0.26 & - \\
\hline & 0.300 & 0.05 & 0.05 & 0.06 & 0.08 & 0.16 & 0.30 & - & - \\
\hline & 0.400 & 0.06 & 0.06 & 0.08 & 0.20 & 0.36 & - & - & - \\
\hline & 0.500 & 0.06 & 0.08 & 0.25 & 0.43 & - & - & - & - \\
\hline & 0.600 & 0.08 & 0.32 & 0.56 & - & - & - & - & - \\
\hline & 0.700 & 0.45 & 0.74 & - & - & - & - & - & - \\
\hline & 0.800 & 1.05 & - & - & - & - & - & - & - \\
\hline
\end{tabular}

Although the planner improves social welfare for all combination of weights, the benefits to each agent differ across the various cases. Tables 9, 10 and 11 show the changes in utility for $P, R$, and $B$ respectively. Whenever the planner controls the run by increasing capital $P$ and $R$ are always better off. For the most part, $B$ also gains, except for the perverse cases we mentioned earlier where the intermediation spread is pushed negative.

Table 9: \% Change in P's Welfare: Constrained Planner vs. Competitive Equilibrium

\begin{tabular}{|c|c|c|c|c|c|c|c|c|c|}
\hline & \multicolumn{8}{|c|}{$w^{R}$} \\
\hline & & 0.100 & 0.200 & 0.300 & 0.400 & 0.500 & 0.600 & 0.700 & 0.800 \\
\hline \multirow{8}{*}{$w^{P}$} & 0.100 & $-0.81 \%$ & $-0.86 \%$ & $-0.92 \%$ & $-0.97 \%$ & $1.89 \%$ & $1.91 \%$ & $1.97 \%$ & $2.12 \%$ \\
\hline & 0.200 & $-0.68 \%$ & $-0.72 \%$ & $-0.76 \%$ & $1.88 \%$ & $1.91 \%$ & $2.00 \%$ & $2.16 \%$ & - \\
\hline & 0.300 & $-0.58 \%$ & $-0.61 \%$ & $-0.64 \%$ & $1.91 \%$ & $2.04 \%$ & $2.21 \%$ & - & - \\
\hline & 0.400 & $-0.49 \%$ & $-0.51 \%$ & $1.91 \%$ & $2.09 \%$ & $2.28 \%$ & - & - & $\begin{array}{ll}- & -1\end{array}$ \\
\hline & 0.500 & $-0.42 \%$ & $1.90 \%$ & $2.15 \%$ & $2.35 \%$ & - & - & - & - \\
\hline & 0.600 & $1.90 \%$ & $2.24 \%$ & $2.48 \%$ & - & - & - & - & - \\
\hline & 0.700 & $2.39 \%$ & $2.64 \%$ & - & - & - & - & - & - \\
\hline & 0.800 & $2.89 \%$ & - & - & - & - & - & - & - \\
\hline
\end{tabular}

The combinations of the weights which are shaded purple feature large increases in liquid asset holdings by the bank, big increases in the lending rate (and the intermediation spread), and a collapse of investment. These combinations are designed to improve the welfare of $B$ and the collateral consequence is a reduction in utility for $R$ and $P$. The loss for $R$ is especially large because the planner is still letting $B$ gamble so the run risk is not completely eliminated and when a run occurs it is disastrous for $R$. 
Table 10: \% Change in R's Welfare: Constrained Planner vs. Competitive Equilibrium

\begin{tabular}{|c|c|c|c|c|c|c|c|c|c|}
\hline & \multicolumn{8}{|c|}{$w^{R}$} \\
\hline & & 0.100 & 0.200 & 0.300 & 0.400 & 0.500 & 0.600 & 0.700 & 0.800 \\
\hline \multirow{8}{*}{$w^{P}$} & 0.100 & $-4.30 \%$ & $-4.28 \%$ & $-4.26 \%$ & $-3.82 \%$ & $2.20 \%$ & $2.24 \%$ & $2.28 \%$ & $2.34 \%$ \\
\hline & 0.200 & $-4.37 \%$ & $-4.35 \%$ & $-4.32 \%$ & $2.26 \%$ & $2.23 \%$ & $2.30 \%$ & $2.34 \%$ & - \\
\hline & 0.300 & $-4.44 \%$ & $-4.42 \%$ & $-4.25 \%$ & $2.23 \%$ & $2.31 \%$ & $2.35 \%$ & - & - \\
\hline & 0.400 & $-4.52 \%$ & $-4.49 \%$ & $2.23 \%$ & $2.33 \%$ & $2.34 \%$ & - & - & - \\
\hline & 0.500 & $-4.60 \%$ & $2.22 \%$ & $2.34 \%$ & $2.31 \%$ & - & - & - & - \\
\hline & 0.600 & $2.22 \%$ & $2.34 \%$ & $2.24 \%$ & - & - & - & - & - \\
\hline & 0.700 & $2.24 \%$ & $2.06 \%$ & - & - & - & - & - & - \\
\hline & 0.800 & $1.53 \%$ & - & - & - & - & - & - & - \\
\hline
\end{tabular}

Table 11: \% Change in B's Welfare: Constrained Planner vs. Competitive Equilibrium

\begin{tabular}{|c|c|c|c|c|c|c|c|c|c|}
\hline & \multicolumn{8}{|c|}{$w^{R}$} \\
\hline & & 0.100 & 0.200 & 0.300 & 0.400 & 0.500 & 0.600 & 0.700 & 0.800 \\
\hline \multirow{8}{*}{$w^{P}$} & 0.100 & $9.11 \%$ & $9.11 \%$ & $9.11 \%$ & $8.78 \%$ & $1.90 \%$ & $1.84 \%$ & $1.68 \%$ & $1.32 \%$ \\
\hline & 0.200 & $9.09 \%$ & $9.10 \%$ & $9.10 \%$ & $1.91 \%$ & $1.84 \%$ & $1.61 \%$ & $1.21 \%$ & - \\
\hline & 0.300 & $9.06 \%$ & $9.07 \%$ & $8.97 \%$ & $1.85 \%$ & $1.52 \%$ & $1.07 \%$ & - & - \\
\hline & 0.400 & $9.02 \%$ & $9.03 \%$ & $1.85 \%$ & $1.41 \%$ & $0.87 \%$ & - & - & - \\
\hline & 0.500 & $8.97 \%$ & $1.86 \%$ & $1.24 \%$ & $0.63 \%$ & - & - & - & - \\
\hline & 0.600 & $1.87 \%$ & $0.99 \%$ & $0.20 \%$ & - & - & - & - & - \\
\hline & 0.700 & $0.57 \%$ & $-0.45 \%$ & - & - & - & - & - & - \\
\hline & 0.800 & $-1.59 \%$ & - & - & - & - & - & - & - \\
\hline
\end{tabular}

\section{Regulation}

We now explore how the planner's solution can be decentralizing via various regulatory interventions. Section 4.1 discusses the effects when the tools are used in isolation. In the interest of space, we perform comparative statics with respect to these options and show their effect on selected variables in order to highlight explain the main effects of the different tools. Section 4.2 discusses how they regulations can be optimally combined the bring the regulated economy closer to the planner's solution. ${ }^{25}$ We will see that a critical distinction is whether the competitive equilibrium exhibits over-investment and under-investment. Different tools are needed in for these cases, but in either case the best strategy requires deploying multiple regulations.

\subsection{Single Regulations}

We consider five regulatory tools: capital requirements, liquidity requirements, deposit insurance, loan-to-value requirements, and a tax on dividends. We study how each tool individually affects the

\footnotetext{
${ }^{25}$ We consider a Ramsey planner who chooses the given tool optimally given the optimizing conditions and budget sets in the competitive economy.
} 
two externalities in the model, i.e. how each changes the optimality condition (33) that governs the banks' risk-taking, and the probability of a bank run.

\subsubsection{Capital Requirements}

Capital regulation requires the bank to hold a certain percentage of equity for every unit of risky loans extended, formally

$$
C R \cdot I \leq E^{B}+P_{e q}^{B} x_{e q}^{R} \quad\left(\lambda^{C R}\right)
$$

where $C R$ is the capital requirement and $\lambda^{C R}$ is the Lagrange multiplier on the capital constraint. ${ }^{26}$ We have written the regulation in terms of risk-weighted assets, so that there is no capital charge for the riskless liquid asset (and we have set the risk weight on loans to be equal to one).

There are three ways that capital regulation, if is becomes a binding constraint, can influence behavior. First, it introduces a wedge in equation (33):

$$
\sum_{s \notin s^{D}} \lambda_{3 s}^{B, n o-r u n}\left[V_{3 s}^{I}\left(1+r^{I}\right)-\left(1+r_{3}^{D}\right)\right]=\lambda^{C R} C R \frac{E Q}{E^{B}}>0 .
$$

So as expected, stricter capital requirements reduce the desire of the bank to take excessive risk. This consideration pushes investment down.

From proposition 1 and budget constraints (23) and (24), we get that $L I Q_{1}=\delta \cdot D^{R}$ and $D^{R}=$ $\frac{I-E Q}{1-\delta}$. Substituting these in (1), we get that

$$
q=\left(1-\delta-\xi \frac{1-\delta}{1-C R}\right)^{2}
$$

Through this second channel higher capital requirements reduce the probability of a bank-run, which makes savers more willing to lend and the entrepreneur to borrow, which should push investment up.

Finally, substituting equity financing for deposit financing marginally allows the bank to hold less liquidity to serve the impatient households, which incrementally frees up resources to be invested in the risky technology. Taking account of all three forces, investment in the risky project increases for higher capital requirements.

Figure 2 shows the change in investment, the probability of a run, the deposit rate and the repayment rate on deposits for different values of each of the regulations that we analyze. To make this comparison across regulations, we start at the competitive equilibrium and then successively solve the model for different levels of the each regulation (except deposit insurance which is either on or off). The horizontal axis shows increments in the tightness of regulation, so in the case of capital regulation each step is a 5\% increase in capital (from its initial level of 14.8 percent).

The drop in the probability of a bank-run is beneficial for all agents. So the utility for each agent rises up to the point that capital requirements are high enough to bring $q$ down to zero (Figure

\footnotetext{
${ }^{26}$ It can be easily shown that $P_{e q}^{B}=1$ under binding capital requirements.
} 
3). But, in addition to the main effect, there are other effects that are more easily identified when the positive effects of lowering $q$ has been exhausted. Once bank-runs are eliminated, $P$ can only be better-off if risky investment increases. Because capital requirements reduce the bank's need to carry the liquid assets, investment goes up as capital rises and deposits fall, leaving $P$ is better-off.

$B$ is taking excessive risks because she is protected by limited liability. Being a price taker, she does not factor in the effect that her risk-taking has on the deposit rate. The more leverage the bank uses in its funding, the lower is the percentage repayment on deposits, $V_{3 b}^{D}\left(1+r^{D}\right)=\frac{I}{D^{R}} V_{3 b}^{I}(1+$ $\left.r^{I}\right)$. $B$ neglects this in her optimal decision, but $R$ takes it into consideration when he optimally chooses his level of deposits (equation (16)) and insists on a higher deposit rate. Capital regulation partially corrects this market failure, and it results in lower borrowing costs for the bank, since with more equity deposits are better protected in bankruptcy. This consideration is why $B^{\prime} s$ welfare improves even beyond the point that $q=0$. However, as the percentage repayment on deposits in the bankruptcy state $\left(V_{3 b}^{D}\right)$ gets closer to one, the positive feedback effect on the borrowing cost diminishes and $B$ is relatively less better-off.

In the equilibrium that we are considering, all the savings in the bank comes from $R$. In this case, it immediately follows that $R^{\prime} s$ utility begins declining once capital regulation tightened beyond what is needed to set $q=0 . R$ could have already chosen to invest more in equity and less in deposits and saved more or less overall. So moving him away from his initial allocation will reduce his utility.

Capital regulation is effective in stopping a run because it forces all savers (patient and impatient) to buy equity at time 1 . The higher equity makes deposits safer (at both time 2 and 3 ). But at time 2 this creates a subtle problem. The impatient savers will withdraw their deposits and sell their equity. The regulation means that they will be selling more equity than otherwise, which incrementally pushes down the price of equity in the second period. So the patient depositors benefit from being able to buy this equity and get a bigger capital gain than in the competitive equilibrium. On the margin, this creates a new incentive for the patient depositors to withdraw deposits to buy equity. Although the incentive compatibility constraint (35) is satisfied when only capital regulation is used, the aforementioned effect can encourage patient depositors to withdraw early when capital requirements are used in combination with other regulation which suppress long-term deposit rates as we discuss in section 4.2 .

\subsubsection{Deposit Insurance}

A straightforward way to eliminate the possibility of a bank-run is the introduction of full deposit insurance. This resolves the coordination problem among patient depositors, who instead of running would rather keep their deposits in the bank and be repaid with whatever is available in period 3. Deposit insurance eliminates the bad equilibrium, and in the original Diamond-Dybvig set-up this is a powerful regulation that unambiguously improve outcomes. ${ }^{27}$

\footnotetext{
${ }^{27}$ Contrary to deposit insurance, a Lender of Last Resort (LOLR) is not always able to eliminate the bad equilibrium. Credible commitment requires that any liquidity assistance that is provided be fully collateralized by the value of the
} 
In our model deposit insurance has two downsides that are absent from the original DiamondDybvig model. One is that there can still be losses on deposits in the bad state of nature. This means that taxes will need to be levied to repay depositors in these cases. For simplicity, we assume that the planner levies lump-sum taxes on patient savers to pay for the deposit insurance. The lump-sum taxes are equal to the loss given default on deposits, i.e. $T_{3 b}=(1-\delta) D^{R}\left(1+r_{3}^{D}\right)-V_{3 b}^{I} I\left(1+r^{I}\right)-$ $L I Q_{2}$. Because the tax is lump-sum and independent of whether savers hold deposits or not, the tax does not affect the pricing of deposits. Instead, the savers act as if deposits are risk-free. Thus, $R^{\prime} s$ optimality condition (16) becomes $-\lambda_{1}^{R}+\lambda_{2}^{R, i, n o-r u n}+\left(1+r_{3}^{D}\right) \sum_{s} \lambda_{3 s}^{R, p, n o-r u n}=0$, i.e. $R$ ignores the fact that bank will default in state $3 b$.

This leads to the second problem associated with deposit insurance. The market discipline that $R$ was previously exerting through higher interest rates vanishes, so the cost of deposits for $B$ falls, which gives $B$ an even stronger incentive to take additional risk and exploit limited liability. Thus, deposit insurance eliminates the bank run, but does not correct for the risk-taking externality. ${ }^{28}$

Not surprisingly, $B$ substitutes towards more deposit financing (notice that the capital adequacy ratio in Figure 2 falls) and increased lending which leads to more investment (Figure 2). Because the bank needs to hold more liquid assets to serve early withdrawals and its liquidity ratio increases.

Eliminating the bank-run is Pareto improving. Figure 3 shows that welfare goes up for all agents once deposit insurance is introduced. However, gains are not equally distributed. The easiest way to see the marginal effects of deposit insurance is to compare its effect to the economy where capital requirements are just high enough eliminate the risk of a run. Relative to this benchmark, $R$ is relatively better-off under capital regulation, because he does not price-in the cost of deposit insurance. In contrast, $B$ is relatively better-off under deposit insurance, because she can better exploit limited liability and the option to default. $P^{\prime} s$ welfare will depend on the level of investment, since in this comparison the probability of a run is zero under either policy. Investment is higher under deposit insurance than with capital requirements, because the bank gambles by making extra loans. In particular, deposit insurance results in a $10.5 \%$ increase in investment compared to the competitive equilibrium, while a capital requirement which sets $q=0$ results in a $9.2 \%$ increase.

bank's assets in the worst possible realization in period 3. But, there is nothing that guarantees that there are sufficient resources to permit this and in the calibrated equilibrium we examine this condition is not satisfied, thus we do not consider a LOLR in our analysis (see Rochet and Vives (2004)). We also do not study the effects of suspension of convertibility. Ennis and Keister (2009) show that deposit freezes, which are ex-post efficient, do not eliminate the possibility of a bank-run.

${ }^{28}$ Admati et al. (2012) also consider a model where government guarantees exacerbate the incentive of banks to increase their leverage and take risk. We discuss later how deposit insurance and higher capital requirement can be optimally combined to achieve certain planning outcomes. Cooper and Ross (2002) argue that a combination of deposit insurance and capital requirements is desirable because it simultaneously eliminates bank runs and corrects the distorted incentives for risk-shifting. Their analysis abstracts from the general equilibrium effects of these two polices on the deposit rate and the saving decision to smooth intertemporal consumption. This is a powerful channel which suppresses deposit rates and can allow the bank to take on more risk. 


\subsubsection{Liquidity Regulation}

The bank in the competitive equilibrium invests in safe assets only to satisfy early deposit withdrawals. From proposition $1, L I Q_{1}=\delta \cdot D^{R}$ and $L I Q_{2}=0$. This is privately optimal because when the bank in making its asset allocation it worries only about the rates of return on assets in the good and medium states. The marginal cost of funds is perceived as the deposit rate which exceeds the return on the safe asset, making the safe asset an inferior investment option. However, higher liquidity can reduce the probability of a bank-run, which the bank does not internalize.

Define the liquidity regulation as a constraint that requires

$$
L I Q_{1} \geq L R \cdot I \quad\left(\lambda^{L R}\right),
$$

where $L R$ is the liquidity requirement and $\lambda^{L R}$ is the Lagrange multiplier on the liquidity constraint. Substituting equation (24) in (1) and using (55) we get that

$$
q=\left(1-\delta \frac{1+\xi_{\frac{1}{L R}}}{1-\frac{L I Q_{2}}{L I Q_{1}}}\right)^{2}
$$

Thus, liquidity regulation can reduce the probability of a bank-run only if it induces positive liquidity holdings in period 2 after the withdrawals by the impatient depositors have occurred. This result should not be surprising: The social benefits of holding safe asset only are present when the bank holds enough liquid assets to raise the liquidation value of the bank in the bad state. If the bank's liquid asset holdings are only sufficient to cover the expected second period withdrawals, then the liquidation value of the bank in the bad state is unaffected.

Combining the first order conditions for $L I Q_{1}, L I Q_{2}$ and $D^{R}$ under binding liquidity regulation, the bank will hold positive liquidity in period 2 if

$$
\lambda^{L R} \geq(1-\delta) r^{D} \frac{E^{B}}{E Q} \sum_{s \notin s^{D}} \lambda_{3 s}^{B, n o-r u n},
$$

which is satisfied for sufficiently high liquidity regulation.

There are two opposing forces with respect to the effect of liquidity regulation on risk-taking incentives. On one hand, the bank has to hold more liquidity per unit of risky investment which makes investment more expensive and less attractive. On the other hand, higher levels of liquid asset holdings make it possible to attract more deposit financing, which raises the temptation to gamble. Equation (33) becomes

$$
\sum_{s \notin s^{D}} \lambda_{3 s}^{B, n o-r u n}\left[V_{3 s}^{I}\left(1+r^{I}\right)-\left(1+r_{3}^{D}\right)\right]=\lambda^{L R}\left(L R-\frac{\delta}{1-\delta}\right) \frac{E Q}{E^{B}},
$$

which is positive for high enough $L R$.

Besides trying to reduce the probability of a bank-run, the other motivation for liquidity reg- 
ulation is to limit the losses from default that are induced by $B^{\prime} s$ excessive lending. With limited liability the bank fails to internalize actions that make deposits safer. Liquidity regulation helps combat this problem by directly altering $B^{\prime} s$ asset mix. When forced to hold liquid assets in place of loans, the bank perceives its return on assets to have fallen. But, because the bank ignores the corresponding drop in the cost of its deposit funding, it will seek a higher return on loans to compensate for the lower yield on the safe asset. With the decreasing returns to scale technology operated by $P$, this requires a smaller loan. So liquidity regulation leads to a first-order reduction in lending and investment as seen in Figure 2. In the figure, the increments to liquidity on the horizontal axis are $0.5 \%$.

The imposition of liquidity regulation has asymmetric effects on the different agents. Assuming that the increase in liquidity requirements is sufficiently high, the reduction in the probability of a bank-run helps $P$. But the large drop in investment makes $P$ worse off. Overall, $P$ is slightly worse-off (Figure 3).

Liquidity regulation reduces the ability of $B$ to take advantage of her limited liability, but can also helps her by lowering the bank-run probability. An initial increase in the liquidity requirement does not reduce the probability of a bank-run, because the bank continues to choose $L I Q_{2}=0$. As discussed in section 3.3, $B$ could conceivably be better-off if the gap between the deposit rate and the lending rate widened sufficiently. But, liquidity regulation by itself cannot induce this kind of change in the intermediation spread, because the bank increases it demand for deposits and is willing to pay a higher deposit rate. The fact that deposits are also safer works in the opposite direction and the deposit rate remains roughly unchanged (Figure 2). Thus, $B^{\prime} s$ welfare initially drops. As liquidity requirements becomes stricter, the bank starts holding positive liquidity in period 2 and the probability of a bank-run drops. This raises $B^{\prime} s$ welfare, but even so it remains lower than in the competitive equilibrium when it can gamble relatively more.

$R$ is better off than without the regulation. The improvement comes because the size of the default that he faces in the bad state is meaningfully reduced and because the probability of a bankrun decreases. The only way that $R$ previously was able to hedge this risk was by demanding a higher interest rate on deposits, which imperfectly corrects the problem. Given the ability to now re-optimize his mix of deposits and equity, he chooses more deposits and less equity and is strictly better off than before. ${ }^{29}$

\subsubsection{Tax on Dividends}

We next consider a tax on dividends. Viewed independently this tool makes little sense because it does not help correct the two externalities in the model. However, we will see subsequently that when it is used in conjunction with other regulations, it can be a valuable addition to the regulatory toolkit.

\footnotetext{
${ }^{29}$ Liquidity requirements increase the amount of investment in the liquid asset, which will serve early deposit withdrawals at $t=2$, and correspondingly reduce the amount of investment in the risky asset. All else equal, this helps the early consumers. See Fahri et al. (2009) for a Diamond-Dybvig framework with private markets in the interim period, where liquidity requirements improve liquidity provision and increase ex-ante welfare of depositors.
} 
We consider a tax policy that only distorts the marginal value of holding equity. We assume that tax revenues are returned lump-sum to shareholders in proportion to the number of shares that each owns.

The budget constraint (13) of $R$ in state $3 s$ is written

$$
c_{3 s}^{R, p, n o-r u n} \leq x_{s e c}^{R} D P S_{3 s}\left(1-\tau_{D i v}\right)+V_{3 s}^{D} D^{R}\left(1+\bar{r}^{D}\right)+L I Q_{2}^{R}+T_{3 s}^{R} \quad\left(\lambda_{3 s}^{R, p, n o-r u n}\right),
$$

where $\tau_{D i v}$ is the marginal tax on dividends and $T_{3 s}^{R}=\tau_{D i v} x_{s e c}^{R} D P S_{3 s}$. The optimizing condition with respect to equity purchases in the secondary market becomes

$$
-\lambda_{2}^{R, p, n o-r u n} P_{s e c}+\left(1-\tau_{D i v}\right) \sum_{s} \lambda_{3 s}^{R, p, n o-r u n} D P S_{3 s}=0 .
$$

Dividend taxes reduce the price of equity in the secondary market and thus reduce the initial willingness of $R$ buy bank equity(through equation (30)). As a result, $R$ shifts towards saving more via deposits and this pushes the deposit rate down. The increased supply of deposits, combined with the lower deposit rate, allows $B$ to take further advantage of her limited liability. This happens because the dividend tax does not affect the marginal incentive to take risk. The budget constraint of $B$ in state $3 s$ becomes

$c_{3 s}^{B, \text { no-run }} \leq \frac{E^{B}}{E Q} \max \left[V_{3 s}^{I} I\left(1+r^{I}\right)+L I Q_{2}-\left((1-\delta) D^{R}\right)\left(1+r_{3}^{D}\right), 0\right]\left(1-\tau_{D i v}\right)+T_{3 s}^{B}+e_{3 s}^{B} \quad\left(\lambda_{3 s}^{B, n o-r u n}\right)$,

where $T_{3 s}^{B}=\tau_{D i v} E^{B} D P S_{3 s}$ and the equilibrium condition for the intermediation spread (33) is the same.

$R$ is clearly worse-off, because he is induced to save through deposits and the deposit rate falls (Figure (3)). So $R^{\prime} s$ total savings decline. $P$ is worse-off because dividend taxes do not address the bank-run externality and the lower savings by $R$ supports lower investment. $B$ raises more deposits and hence holds more liquidity, and is better-off for several reasons. Her ability to take risk is not reduced. The spread between the borrowing and lending rate widens, and she gets a higher portion of the profits. So viewed in isolation this is not a particularly attractive regulation.

\subsubsection{Loan-to-Value Regulation}

Finally, we consider a restriction on $P^{\prime} s$ ability to take risk that imposes a minimum loan downpayment. Such regulation can be written as

$$
\begin{aligned}
& \frac{I}{I+I^{P}} \leq L T V \\
& I^{P} \geq \frac{1-L T V}{L T V} I \quad\left(\lambda^{L T V}\right),
\end{aligned}
$$

where $L T V \leq 1$ is the loan-to-value requirement and $\lambda^{L T V}$ is the Lagrange multiplier on the regulatory constraint. In the unconstrained competitive equilibrium, $P$ borrows the full amount needed to 
fund the project, so $I^{P}=0$ and $L T V=1$. A lower $L T V$ introduces a wedge between the marginal productivity of investment and the loan rate. The adjusted optimality condition for $I$ becomes:

$$
A_{3 g} F^{\prime}\left[\left(1+\frac{1-L T V}{L T V}\right) I\right]-\left(1+r^{I}\right)=\frac{\lambda^{L T V}}{\lambda_{3 g}^{P, n o^{-r u n}}} \frac{1-L T V}{L T V} .
$$

This kind of regulation also interferes with $P^{\prime} s$ ability to smooth consumption. The new optimality condition (8) when the LTV ratio is binding is:

$$
\lambda_{1}^{P}=a A_{3 g}\left[\left(1+\frac{1-L T V}{L T V}\right) I\right]^{a-1} \lambda_{3 g}^{P, n o-r u n}+\xi \cdot \sum_{s} \lambda_{3 s}^{P, r u n}+\lambda^{L T V}
$$

Loan-to-value regulation increases the percentage repayment on loan in states $3 m$ and $3 b$ where $P$ chooses to default $\left(V_{3 m}^{I}\right.$ and $V_{3 b}^{I}$ ). The bank ignores effect on $V_{3 b}^{I}$ (when it also defaults), but it will account for the increase in $V_{3 m}^{I}$ and offer a lower loan rate $r^{I}$. With a lower borrowing cost $P$ would like to take more risk, but the binding LTV requirements force him to take a smaller loan (Figure (2))..$^{30}$

The LTV regulation create several opposing incentives for the bank and the saver. Forcing $P$ to have some skin in the game, makes deposits safer in the bad state and equity returns higher in the medium state. In this calibration, $R$ responds by shifting toward saving more with deposits.

The bank finds itself with lower loan demand and a higher supply of deposits. It responds to these changes by reducing loans, and raising its investment in the safe asset (see Figure (2)). But the bank does not get to the point where it carries liquid assets into period 3, i.e. $L I Q_{2}$ is still zero. Consequently, the probability of a bank-run goes up (see section 4.1.3).

Taking account of all the effects, $R$ is worse-off (Figure (3)). $B$ is also worse-off because her ability to take risk is reduced and $q$ is higher, despite the fact that her equity is less risky conditional on bank survival. Finally, $P$ is worse-off because he is required to reduce his consumption in the initial period where he is poor. So even though this regulation does attack the risk-taking externality, it does not help any of the agents when it is used alone.

\subsection{Optimal Regulatory Mix}

Recall that the social planner had three very different approaches to improving on the competitive equilibrium which differed according to the weights in the social welfare function. This tells us that any attempt to implement the social planner's allocations using regulation will also involve different regulatory tools depending on the weights in the social welfare function. To see this concretely, we first consider six points in the grid that correspond to different types of allocations that the planner might want to implement, and then share some general remarks.

First, take a case like $w^{P}=w^{R}=0.2$ and $w^{B}=0.6$, where the planner is mostly concerned with the welfare of the bank. In these scenarios, we saw that the planner chooses higher liquidity which

\footnotetext{
${ }^{30}$ In figure 3 , each increment to the LTV represents a $0.05 \%$ decrease.
} 
reduces the probability of a bank-run, without reigning in the bank's ability to gamble. Columns two to four in Table 12 shows the key variables and utility levels for the competitive equilibrium, the constrained social planner, and for the best outcome (in terms of social welfare) that is achievable when the planner can only adjust liquidity regulation. We see that using liquidity regulation alone the planner can improve upon the competitive equilibrium, but cannot completely implement the allocations that maximize social welfare.

The failure to replicate the planner's preferred allocations comes because the bank's capital ratio actually goes up which limits the bank's ability to gamble. So bank ends up being barely worse off relative to the competitive equilibrium. The only way to approximate the planning outcome, therefore, is to combine the liquidity regulation with other regulations that help the bank.

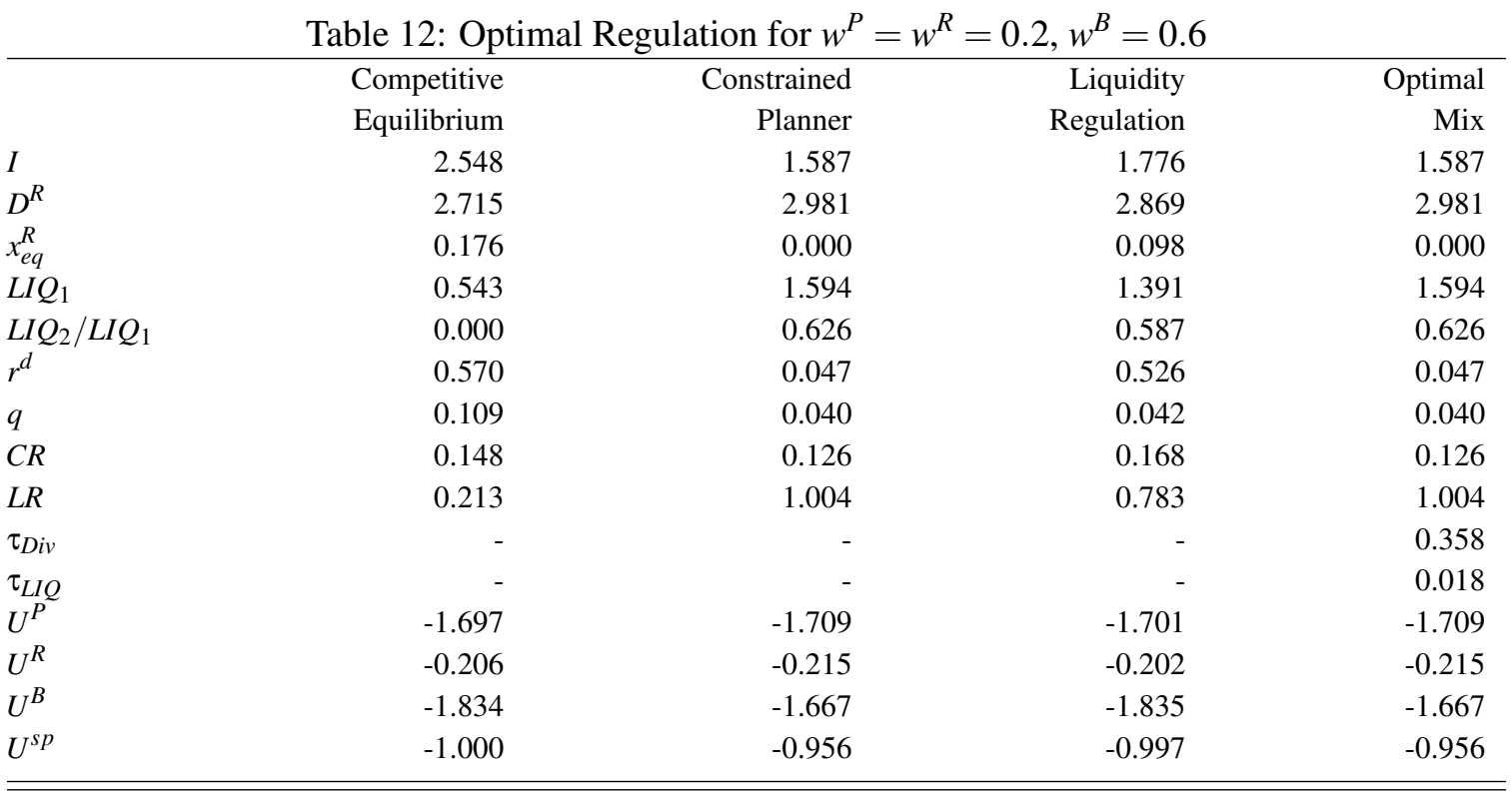

There are several ways that this can be done. The planner's allocation maximizes the bank's leverage, while setting the deposit rate such that the incentive compatibility constraint (35) is satisfied. To increase leverage, a tax on dividends can be imposed. As described in section 4.1.4, this tax is not redistributive, but just makes equity investment less attractive. But, if we impose a stiff enough dividend tax to stop the saver from buying bank equity, the saver also concludes that deposits are unattractive relative to investing directly in the liquid asset.

To replicate exactly the planner's allocations, a tax on the safe asset can be added to the mix. ${ }^{31}$ This makes the effective return on owning the liquid asset negative, which stops the saver from using that asset. The bank will still buy this asset provided the after-tax return remains higher than can be obtained from making loans and liquidating them early. The last column in Table 12 shows the results when a small tax on safe assets, along with a tax on dividends are combined with the liquidity regulation. Using all these regulations we can mimic the planning allocations.

\footnotetext{
${ }^{31}$ The tax revenues are redistributed lump-sum to the respective agents taxed within the same period and state of the world.
} 
Consider next a case where the planner cares almost as much about each of the agents, such as when $w^{P}=w^{R}=0.35$ and $w^{B}=0.3$. In this case, and others in the blue region region in Table 3 , the planner chooses to reduce the probability of a bank-run with more capital. In the blue region, the planner chooses lower investment than in the competitive equilibrium. Columns 2 to 4 in Table 13 show the competitive equilibrium, the constrained social planner's allocations and the equilibrium with the optimal choice when only a capital requirement can be implemented.

Table 13: Optimal Regulation for $w^{P}=w^{R}=0.35, w^{B}=0.3$

\begin{tabular}{|c|c|c|c|c|c|}
\hline & Competitive & Constrained & Capital & Optimal & Alternative \\
\hline & Equilibrium & Planner & Regulation & $\operatorname{Mix}$ & Mix \\
\hline$I$ & 2.548 & 2.481 & 2.782 & 2.486 & 2.489 \\
\hline$D^{R}$ & 2.715 & 1.577 & 1.739 & 1.554 & 1.557 \\
\hline$x_{e q}^{R}$ & 0.176 & 1.019 & 1.191 & 1.043 & 1.615 \\
\hline$L I Q_{1}$ & 0.543 & 0.316 & 0.348 & 0.311 & 0.311 \\
\hline$L I Q_{2} / L I Q_{1}$ & 0.000 & 0.000 & 0.000 & 0.000 & 0.000 \\
\hline$r^{d}$ & 0.570 & 0.080 & 0.464 & 0.079 & 0.132 \\
\hline$q$ & 0.109 & 0.000 & 0.000 & 0.000 & 0.000 \\
\hline$C R$ & 0.148 & 0.491 & 0.500 & 0.500 & 0.500 \\
\hline$L R$ & 0.213 & 0.127 & 0.125 & 0.125 & 0.125 \\
\hline$\tau_{D i v}$ & - & - & - & 0.505 & 0.481 \\
\hline$\tau_{L I Q}$ & - & - & - & 0.569 & 0.500 \\
\hline$U^{P}$ & -1.697 & -1.664 & -1.656 & -1.664 & -1.664 \\
\hline$U^{R}$ & -0.206 & -0.201 & -0.201 & -0.201 & -0.200 \\
\hline$U^{B}$ & -1.834 & -1.800 & -1.825 & -1.801 & -1.836 \\
\hline$U^{s p}$ & -1.000 & -0.980 & -0.982 & -0.980 & -0.983 \\
\hline
\end{tabular}

With capital requirements as the single regulatory tool, the optimal choice brings the probability of a bank-run down to zero, but resulting investment is higher than what the constrained planner would choose. ${ }^{32}$ So although capital regulation makes each agent better off than in the competitive equilibrium, it does not get all the way to the planner's allocations.

A direct way to bring investment down while controlling for the bank-run is to combine capital regulation with a tax on dividends. These two tools interact well. The capital requirement can be used to eliminate the bank-run. The dividend tax starves the bank of equity financing, but because of the binding capital requirement, the bank cannot freely replace equity finance with deposit financing. When the level of these two tools are set optimally the bank cannot gamble excessively and lending and investment must fall. However, the combination of capital requirements with a tax on dividends pushes down both the long-run deposit rate and the equity price in the secondary market. As a result, the incentive of patient depositors to withdraw early increases and additional policy interventions are needed to satisfy the incentive compatibility constraint (35) while keeping the long-term rate and investment low.

\footnotetext{
${ }^{32}$ The optimal level of capital requirement depends on the liquidation value of the risky investment. From equation (54) and for $L I Q_{2}=0$, the capital requirement that brings the probability of a bank-run down to zero is equal to $1-\xi$. This applies for any functional form for $q$ as the probability of being served during a run is equal to 1 . Capital requirement are sufficient to control the probability of a bank-run in this environment.
} 
A direct way to reduce the incentives for withdrawing is to impose a tax on liquid asset holdings, which makes equity purchases in the secondary market more attractive than saving through the liquid asset and raises secondary equity prices. The equilibrium allocations for the optimal mix of capital requirements, dividend tax and tax on liquid assets held by $R$, which are reported in column 4 of table 13, mimic the social planner's solution for this set of weights. Broadening the policy mix, to impose a global tax on liquid assets held by the bank as well does not perform as efficiently. First, the tax cannot exceed the liquidation cost, $1-\xi$, of long-term investment, otherwise the bank would not hold liquid assets to satisfy early withdrawals by impatient depositors. The fifth column in table 13 reports the equilibrium allocation when a tax on liquid assets of $50 \%(=1-\xi)$ is imposed globally. Such a policy induces the bank to issue equity at a discount, since holding liquidity to meet early withdrawals in costly on the margin, and the equity price in the initial period falls $\left(P_{e q}^{B}=0.65\right)$. Although risky investment falls, as intended, the welfare losses to $B$ outweigh the gains to $R$ and social welfare is lower than in the case that capital requirement are the only policy chosen optimally.

The analysis above highlights the difficulties in suppressing investment while controlling for the run with higher capital requirements. An alternative way to reduce the amount of risky investment would be to supplement capital requirements with liquidity requirements. Capital requirement can be optimally chosen to eliminate the possibility of a run, while liquidity requirement would act as a "tax" on risky investment given that bank should hold more inefficient liquid assets. However, such a combination results in lower social welfare compared to the use of only capital requirements for $w^{P}=w^{R}=0.35$ considered above (see Figure 4 in Appendix B). This is not surprising since liquidity regulation hurts $P$ and $B$ while the gains to $R$ are limited (see section 4.1.3).

However, the combination of capital and liquidity requirements can increase welfare when the planner cares mostly about $R$. For instance, consider another combination in the blue region where $w^{P}=0.2, w^{R}=0.6$ and $w^{B}=0.2$. Table 14 compares the equilibrium allocations when, first, the optimal mix of capital requirements, dividend tax and tax on liquid assets held by $R$, and, second, capital and liquidity requirement, are implemented. Both result in lower investment than the competitive equilibrium while setting the probability of a bank-run to zero, though the latter induce a smaller increase in welfare. ${ }^{33}$

Next consider the green region in Table 3. Throughout the green region, the planner controls the bank-run with higher capital, but chooses higher investment than in the competitive equilibrium. One example is when $w^{P}=w^{R}=0.4$ and $w^{B}=0.2$. Table 15 shows the various possible outcomes for these social welfare weights, which are in line to the ones obtained for the blue region when a combination of capital requirements, dividend tax and tax on liquid assets are used; all that changes is the optimal dividend tax and the tax on liquid assets held by $R$ are lower. In particular, the lower dividend tax allows the bank to attract enough funding to boost its lending.

As the level of investment that the planner targets increases, the importance of the tax on liquid assets diminishes. The reason is that higher levels of investment can be implemented with a smaller

\footnotetext{
${ }^{33}$ The combination of capital and liquidity regulation also increases social welfare and reduces investment for $\left(w^{P}, w^{R}\right) \in\{(0.1,0.5),(0.1,0.6),(0.1,0.7),(0.2,0.5)\}$, which correspond to the blue region.
} 
Table 14: Optimal Regulation for $w^{P}=0.2, w^{R}=0.6, w^{B}=0.2$

\begin{tabular}{|c|c|c|c|c|c|}
\hline & Competitive & Constrained & Capital & Optimal & Capital \& Liquidity \\
\hline & Equilibrium & Planner & Regulation & Mix & Regulation \\
\hline$I$ & 2.548 & 2.536 & 2.782 & 2.536 & 2.435 \\
\hline$D^{R}$ & 2.715 & 1.585 & 1.739 & 1.585 & 1.936 \\
\hline$x_{e q}^{R}$ & 0.176 & 1.068 & 1.191 & 1.068 & 1.017 \\
\hline$L I Q_{1}$ & 0.543 & 0.317 & 0.348 & 0.317 & 0.718 \\
\hline$L I Q_{2} / L I Q_{1}$ & 0.000 & 0.000 & 0.000 & 0.000 & 0.461 \\
\hline$r^{d}$ & 0.570 & 0.137 & 0.464 & 0.137 & 0.473 \\
\hline$q$ & 0.109 & 0.000 & 0.000 & 0.000 & 0.000 \\
\hline$C R$ & 0.148 & 0.500 & 0.500 & 0.500 & 0.500 \\
\hline$L R$ & 0.213 & 0.125 & 0.125 & 0.125 & 0.295 \\
\hline$\tau_{D i v}$ & - & - & - & 0.439 & 0.000 \\
\hline$\tau_{L I Q}$ & - & - & - & 0.487 & 0.000 \\
\hline$U^{P}$ & -1.697 & -1.663 & -1.656 & -1.663 & -1.666 \\
\hline$U^{R}$ & -0.206 & -0.201 & -0.201 & -0.201 & -0.200 \\
\hline$U^{B}$ & -1.834 & -1.805 & -1.825 & -1.805 & -1.825 \\
\hline$U^{s p}$ & -1.000 & -0.979 & -0.982 & -0.979 & -0.980 \\
\hline
\end{tabular}

tax on dividends and after a point the patient savers' incentive compatibility constraint will not bind. Thus, there is not a need to discourage them from holding liquid assets. For example, consider the planner's solution for $w^{P}=0.6, w^{R}=0.2$ and $w^{B}=0.2$ reported in table 16 . The planner chooses higher investment compared to the competitive equilibrium, yet lower than what can be achieved with optimal capital regulation. A smaller tax of dividends can complement capital requirements to bring investment down to the desired level, while satisfying the incentive compatibility constraint. Thus, there is no need to levy a tax on liquid assets to replicate the planner's solution. ${ }^{34}$

Finally, there are other portions of the green region where the dividend tax is not the best tool to combine with capital regulation to approximate the planner's allocations. These situations arise when the weight on $P$ is relatively high and the weight on $B$ is relatively low. In these cases, the planner not only sets investment higher than in the competitive equilibrium, but also higher than the level that results when capital requirements have been used to eliminate a bank-run. One example where this happens is when social planner's weights are $w^{P}=0.6, w^{R}=0.3$ and $w^{B}=0.1$ (Table 17).

To further boost investment once the run risk is absent, the bank's balance sheet must grow. That cannot happen when a dividend tax is implemented. Instead, a subsidy for equity investment would be required - which we rule out as implausible. However, higher investment could be achieved by a combination of capital requirements and deposit insurance. With deposit insurance, the cost of deposits falls and this makes it possible for the bank to raise additional equity so that investment can expand. With deposit insurance on top of capital requirement, $B$ and $P$ are the marginal winners since $B$ can exploit better her limited liability and $P$ receives a bigger loan. $R$ loses on the margin because he has to pay for the deposit insurance that is needed to achieve the desired level of risktaking.

\footnotetext{
${ }^{34}$ This combination is also optimal for $\left(w^{P}, w^{R}\right) \in\{(0.3,0.6),(0.4,0.5)\}$, which correspond to the green region.
} 
Table 15: Optimal Regulation for $w^{P}=w^{R}=0.4, w^{B}=0.2$

\begin{tabular}{|c|c|c|c|c|}
\hline & Competitive & Constrained & Capital & Optimal \\
\hline & Equilibrium & Planner & Regulation & Mix \\
\hline$I$ & 2.548 & 2.587 & 2.782 & 2.587 \\
\hline$D^{R}$ & 2.715 & 1.617 & 1.739 & 1.617 \\
\hline$x_{e q}^{R}$ & 0.176 & 1.093 & 1.191 & 1.093 \\
\hline$L I Q_{1}$ & 0.543 & 0.323 & 0.348 & 0.323 \\
\hline$L I Q_{2} / L I Q_{1}$ & 0.000 & 0.000 & 0.000 & 0.000 \\
\hline$r^{d}$ & 0.570 & 0.199 & 0.464 & 0.199 \\
\hline$q$ & 0.109 & 0.000 & 0.000 & 0.000 \\
\hline$C R$ & 0.148 & 0.500 & 0.500 & 0.500 \\
\hline$L R$ & 0.213 & 0.125 & 0.125 & 0.125 \\
\hline$\tau_{D i v}$ & - & - & - & 0.381 \\
\hline$\tau_{L I Q}$ & - & - & - & 0.456 \\
\hline$U^{P}$ & -1.697 & -1.661 & -1.656 & -1.661 \\
\hline$U^{R}$ & -0.206 & -0.201 & -0.201 & -0.201 \\
\hline$U^{B}$ & -1.834 & -1.808 & -1.825 & -1.808 \\
\hline$U^{s p}$ & -1.000 & -0.980 & -0.982 & -0.980 \\
\hline
\end{tabular}

Rather than focusing on the details of the exact combinations of regulations that appear optimal, we think it is more important to recognize several generic implications of the analysis. First, regardless of which weights the planner places on the different agents, approximating the planner's allocations with just one regulation is impossible. In this model, it takes at least two tools to overcome the various distortions.

Second, the way that the various regulations change behavior is very different. So combining some of them leads to very little improvement. Put differently, it is not correct to conclude that combining any two tools is necessarily enough to correct the two externalities in the model.

Third, the interactions among the regulations are sufficiently subtle that it would be hard to guess which combinations prove to be optimal in this model. We do not want to claim that our model is sufficiently general that the findings necessarily would carry over to all other models. But, attempting to assess different regulations (and to calibrate how they should be set) would be very difficult to do without consulting a range of models. Intuition helps, but at some point it runs out. ${ }^{35}$

Fourth, the main substance challenge arises for the blue region of the parameter space, where the planner would like to eliminate runs and shrink investment. Finding combinations of the regulatory tools that can deliver this outcome is hard for very intuitive reasons. These are all cases where the planner cares more about the savers and borrowers than the banks, so that raising capital standards is the best way to control the run. But, as we have seen higher capital standards on their own lead to higher investment. Introducing deposit insurance makes this problem even worse. Adding liquidity regulation can lead to lower investment, but it can only happen if the required level of liquidity is

\footnotetext{
${ }^{35}$ Multiple externalities operating through different channels would generally require multiple tools to be addressed. In this paper we address the externalities arising from bank-runs and excessive risk-taking. Other type of externalities, for example, can stem from the possibility of fire-sales within the financial system. See Stein (2012), Korinek (2011) and Goodhart et al. (2013) for models which exhibit fire-sales externalities. The latter shows that multiple tools should be used to tackle the inefficiencies within the financial system.
} 
Table 16: Optimal Regulation for $w^{P}=0.6, w^{R}=0.2, w^{B}=0.2$

\begin{tabular}{lrrrr}
\hline & Competitive & Constrained & Capital & Optimal \\
& Equilibrium & Planner & Regulation & Mix \\
$I$ & 2.548 & 2.684 & 2.782 & 2.699 \\
$D^{R}$ & 2.715 & 1.678 & 1.739 & 1.687 \\
$x_{e q}^{R}$ & 0.176 & 1.142 & 1.191 & 1.150 \\
$L I Q_{1}$ & 0.543 & 0.336 & 0.348 & 0.337 \\
$L I Q_{2} / L I Q_{1}$ & 0.000 & 0.000 & 0.000 & 0.000 \\
$r^{d}$ & 0.570 & 0.324 & 0.464 & 0.344 \\
$q$ & 0.109 & 0.000 & 0.000 & 0.000 \\
$C R$ & 0.148 & 0.500 & 0.500 & 0.500 \\
$L R$ & 0.213 & 0.125 & 0.125 & 0.125 \\
$\tau_{D i v}$ & - & - & - & 0.141 \\
$\tau_{L I Q}$ & - & - & - & 0.000 \\
$U^{P}$ & -1.697 & -1.659 & -1.656 & -1.658 \\
$U^{R}$ & -0.206 & -0.201 & -0.201 & -0.201 \\
$U^{B}$ & -1.834 & -1.816 & -1.825 & -1.817 \\
$U^{s p}$ & -1.000 & -0.980 & -0.982 & -0.980 \\
\hline \hline
\end{tabular}

high. In those situations the low relative return on liquid assets greatly reduces the services offered by the bank and social welfare suffers. Likewise, loan to value regulation can be used to shrink investment, but that severely penalizes the borrower and also reduces social welfare.

These considerations lead to using taxes as the second tool with capital regulation. As we described already, dividend taxes make it difficult to keep the patient depositors from withdrawing their money to buy the equity that the impatient investors sell. While taxes on liquid assets can be used to approximate the planner's solution these interventions do not seem very realistic and must be targeted to hit only savers and not intermediaries to be fully effective.

The bottom-line is that if we think excessive gambling and run-risk are the primary considerations that the planner is trying to deal with, the usual regulatory tools do not look like good choices for achieving this outcome. Of course, this statement is conditional on the exact benchmark equilibrium which we consider and need not be generically true. But there are good reasons to think that this objective is likely to be challenging.

\section{Conclusions}

We have examined how many regulations that are often discussed in policy discussions fare in a relatively familiar model of banking. We started from the Diamond and Dybvig (1983) benchmark precisely because it is so thoroughly studied. The modifications that we made trade-off tractability to keep the model relatively simple, against our preference for expanding it to include forces that we believe were important in the global financial crisis.

Therefore, our model includes not only an incentive for lenders and borrowers to take excessive risks, but also the risk of a funding run. This simple pair of features interact in interesting and unexpected ways. We draw several very general lessons from the model that we believe will carry 


\begin{tabular}{rrrr}
\multicolumn{4}{c}{ Table 17: Optimal Regulation for $w^{P}=0.6, w^{R}=0.3, w^{B}=0.1$} \\
Competitive & Constrained & $\begin{array}{c}\text { Capital } \\
\text { Regulation }\end{array}$ & $\begin{array}{r}\text { Capital regulation } \\
\text { \& Deposit Insurance }\end{array}$ \\
Equilibrium & Planner & 2.782 & 2.896 \\
2.548 & 2.848 & 1.739 & 1.810 \\
2.715 & 1.780 & 1.191 & 1.248 \\
0.176 & 1.224 & 0.348 & 0.362 \\
0.543 & 0.356 & 0.000 & 0.000 \\
0.000 & 0.000 & 0.464 & 0.307 \\
0.570 & 0.557 & 0.000 & 0.000 \\
0.109 & 0.000 & 0.500 & 0.500 \\
0.148 & 0.500 & 0.125 & 0.125 \\
0.213 & 0.125 & -1.656 & -1.654 \\
-1.697 & -1.655 & -0.201 & -0.202 \\
-0.206 & -0.201 & -1.825 & -1.819 \\
-1.834 & -1.830 & -0.982 & -0.978 \\
-1.000 & -0.978 & &
\end{tabular}

over to many other models.

First, the unconstrained competitive equilibrium that emerges when private agents do what is individually optimal leads is inefficient. We found many regulatory interventions that made everyone in the economy better off (than they would be in the absence of regulations).

Second, the reason why regulations can lead to Pareto improvements is because of the destructive nature of bank runs. A run hurts savers who may lose deposits, intermediaries that might be wiped out inadvertently, and borrowers who lose credit. Consequently, interventions that reduce the run risk can make everyone better off. But, the policies we found that can prevent runs will differentially favor borrowers, savers and the owners of intermediaries.

Third, taming excessive risk-taking is a trickier problem. The agents that are gambling will not voluntarily want to give up doing so. This makes it unlikely that there will be unanimous support for reigning in the excessive risk-taking.

Fourth, these previous two points suggest that political economy aspects of regulatory design deserve much more study. Discussing financial regulation in models that preclude default is not very interesting. If default was not a fundamental problem, contracts would take care of it, and it would not be such a pervasive feature of the world. Once we recognize that markets are sufficiently incomplete so that default is unavoidable, then it follows that welfare analysis necessarily becomes complicated. A social planner has to put weights on different actors in the model to determine the best allocations. But, where do these weights come from? The gains from lobbying (and other actions) that can determine which regulations are chosen are likely to be high.

A corollary to this observation is that the incentive to engage in regulatory arbitrage is also strong. The incidence of some regulations is very different. If some agents cannot win the political battle to prevent the regulations to being enacted in the first place, then the next step is to try to evade them. The lack of regulatory arbitrage in the model we have studied is one of its main shortcomings.

More generally, we think the kind of analysis that is needed to make additional progress on 
these issues depends on having two ingredients. First, any plausible model has to be cast in a general equilibrium framework. The environment we explored shows that there are many feedback mechanisms that link different agents and shape the efficacy of different regulations.

Second, the model also must include agents that are forward looking. It is precisely because agents can anticipate some of the effects of different restrictions that they will take defensive actions. It is these defensive actions that lead to the feedback mechanisms that must be understood.

Finally, all of the specific conclusions that we have reached about how regulations interact need to be verified in other models. One appealing feature of the model in this paper is that it presumes that the financial system serves multiple purposes. Our bank benefits the borrowers and lenders by facilitating risk-sharing, extending credit, and providing liquidity. We think that shutting down any of these features could create misleading impressions about the effectiveness of different regulations. So including all three of these roles for the financial system in future models is important.

\section{References}

Admati, A.R. and M.F. Hellwig (2013), The Bankers' New Clothes: What's Wrong with Banking and What to Do about It, Princeton University Press, Princeton, NJ.

Admati, A.R., P.M. Demarzo, M.F. Hellwig and P.C. Pfleiderer (2012), 'Debt overhang and capital regulation', Rock Center for Corporate Governance at Stanford University Working Paper No.114

Allen, F. and D. Gale (1997), 'Financial markets, intermediaries, and intertemporal smoothing', Journal of Political Economy 105(3), 523-546.

Allen, F. and D. Gale (1998), 'Optimal financial crisies', Journal of Finance 53(4), 1245-1284.

Allen, F. and D. Gale (2004), 'Financial intermediaries and markets', Econometrica 72(4), 10231061.

Benston, G.J. and C.W. Smith (1976), 'A transactions cost approach to the theory of financial intermediation', Journal of Finance 31(2), 215-231.

Brunnermeier, M.K. and Y. Sannikov (2012), 'The I-theory of money', working paper .

Chari, V.V. and R. Jagannathan (1988), 'Banking panics, information, and rational expectations equilibrium', Journal of Finance 43(3), 749-761.

Citana, A., A. Kajii and A. Villanacci (1998), 'Constrained suboptimality in incomplete markets: A general approach and two applications', Economic Theory 11(3), 495-521.

Cooper, R. and T.W. Ross (1998), 'Bank runs: Liquidity costs and investment distortions', Journal of Monetary Economics 41(1), 27-38. 
Cooper, R. and T.W. Ross (2002), 'Bank runs: Deposit insurance and capital requirements', International Economic Review 43, 55-72.

Detemple, J.B. and P. Gottardi (1998), 'Aggregation, efficiency and mutual fund separation in incomplete markets', Economic Theory 11, 443-455.

Diamond, D.W. and P.H. Dybvig (1983), 'Bank runs, deposit insurance, and liquidity', Journal of Political Economy 91(3), 401-419.

Dubey, P., J. Geanakoplos and M. Shubik (2005), 'Default and punishment in general equilibrium', Econometrica 73(1), 1-37.

Ennis, H.M. and T. Keister (2009), 'Bank runs and institutions: The perils of intervention', American Economic Review 99(4), 1588-1607.

Fahri, E. and J. Tirole (2012), 'Collective moral hazard, maturity mismatch, and systemic bailouts', American Economic Review 102(1), 60-93.

Fahri, E., M. Golosov and A. Tsyvinski (2009), 'A theory of liquidity and regulation of financial intermediation', The Review of Economic Studies 76(3), 973-992.

French et al. (2010), The Squam Lake Report: Fixing the Financial System, Princeton University Press, Princeton, NJ.

Geanakoplos, J. and H. Polemarchakis (1986), 'Existence, regularity, and constrained suboptimality of competitive allocations when the asset market is incomplete', In W. Heller, R. Starr, and D. Starrett (eds.), Essays in Honor of Kenneth Arrow, Vol. 3. Cambridge University Press pp. 6595.

Geanakoplos, J. and W.R. Zame (2013), ‘Collateral equilibrium, I: a basic framework', Economic Theory, in press .

Geanakoplos, John (1997), Promises promises, in W. B.Arthur, S.Durlauf and D.Lane, eds, 'The Economy as an Evolving Complex System II', MA: Addison-Wesley, pp. 285-320.

Gertler, M. and N. Kiyotaki (2013), 'Banking, liquidity and bank runs in an infinite-horizon economy', NBER WP 19129.

Goldstein, I. and A. Pauzner (2005), 'Demand-deposit contracts and the probability of bank runs', Journal of Finance 60(3), 1293-1327.

Gollin, D. (2005), 'Getting income shares right', Journal of Political Economy 110(2), 458-474.

Goodhart, C.A.E, A. K Kashyap, D.P. Tsomocos and A.P. Vardoulakis (2013), 'An integrated framework for analyzing multiple financial regulations', International Journal of Central Banking 9(1), 109-143. 
Jacklin, C.J. and S. Bhattacharya (1988), 'Distinguishing panics and information-based bank runs: Welfare and policy implications', Journal of Political Economy 96(3), 568-592.

Korinek, A. (2011), 'Systemic risk-taking: Amplifications effects, externalities and regulatory responses', ECB WP 1345 .

Morris, S. and H.S. Shin (1998), 'Unique equilibrium in a model of self-fulfilling currency attacks', American Economic Review 88(3), 587-597.

Peck, J. and K. Shell (2003), 'Equilibrium bank runs', Journal of Political Economy 111(1), 103123.

Postlewaite, A. and X. Vives (1987), 'Bank runs as an equilibrium phenomenon', Journal of Political Economy 95(3), 485-491.

Rochet, J-C. and X. Vives (2004), 'Coordination failures and the lender of last resort: Was Bagehot right after all?', Journal of the European Economic Association 2(6), 1116-1147.

Rubinstein, M. (1974), 'An aggregation theorem for securities markets', Journal of Financial Economics 1, 224-244.

Stein, J.C. (2012), 'Monetary policy as financial-stability regulation', The Quarterly Journal of Economics 127(1), 57-95.

Stiglitz, J.E. (1982), 'The inefficiency of the stock market equilibrium', Review of Economic Studies 49(2), 393-410.

Uhlig, H. (2010), 'A model of a systemic bank run', Journal of Monetary Economics 57(1), 78-96.

Zame, W. (1993), 'Efficiency and the role of default when security markets are incomplete', American Economic Review 83(5), 1142-1164.

\section{Appendix A}

\section{Proof of Proposition 1}

Proof. Using (32), the fact that $V_{2 s}^{D}=1$ for $s \notin s^{D}$ and that $\psi_{1}^{B}=\psi_{2}^{B}$, the optimality condition for holding the liquid asset in the bank's balance sheet from period 2 to period $3\left(L I Q_{2}^{B}\right)$ is

$$
-\psi_{1}^{B}+\frac{E^{B}+x_{e q}^{B}}{E^{B}+x_{e q}^{B}+x_{e q}^{R}} \sum_{s \notin s^{D}} \lambda_{3 s}^{B, n o-r u n}=-\psi_{1}^{B}+\frac{\psi_{1}^{B}}{1+r^{D}}<0
$$

since $r^{D}$ is strictly greater then zero from $R$ 's optimality condition (16), $V_{2 s}^{D}<1$ for $s^{D}$ and $R$ has an outside option of investing in the riskless asset. 


\section{Proof of Proposition 2}

Proof. Let, for the sake of simplicity, $r_{2}^{D}=0$. The optimality condition for $D^{B}$ is:

$$
-\lambda_{1}^{B}+\psi_{1}^{B}-\frac{E^{B}+x_{e q}^{B}}{E^{B}+x_{e q}^{B}+x_{e q}^{R}} \sum_{s \notin s^{D}} \lambda_{3 s}^{B, \text { no-run }}\left(1+r_{3}^{D}\right)+\sum_{s} \lambda_{3 s}^{B, n o-r u n} V_{3 s}^{D}\left(1+r_{3}^{D}\right)+\sum_{s} \lambda_{3 s}^{B, \text { run }, \text { paid }} \leq 0
$$

If (64) is zero then $D^{B}>0$, while if it is negative $D^{B}=0$ (short-selling of deposits is not allowed). Substituting (32) in (64) we get:

$$
-\lambda_{1}^{B}+\sum_{s} \lambda_{3 s}^{B, \text { no-run }} V_{3 s}^{D}\left(1+r_{3}^{D}\right)+\sum_{s} \lambda_{3 s}^{B, \text { run,paid }} \leq 0
$$

Let $E Q=E^{B}+x_{e q}^{B}+x_{e q}^{R}$ be the total equity in the bank, which is also the number of share given that $P_{e q}^{B}=1$. The optimality condition with respect to $x_{e q}^{B}$ is:

$$
\begin{aligned}
& -\lambda_{1}^{B}+\psi_{1}^{B}+\frac{x_{e q}^{R}}{E Q} \sum_{s \notin s^{D}} \lambda_{3 s}^{B, n o-r u n} D P S_{2 s}= \\
& -\lambda_{1}^{B}+\sum_{s \notin s^{D}} \lambda_{3 s}^{B, n o-r u n}\left(1+r^{D}\right) \leq \\
& -\sum_{s} \lambda_{3 s}^{B, r u n, p a i d}-\sum_{s} \lambda_{3 s}^{B, n o-r u n} V_{3 s}^{D}\left(1+r_{3}^{D}\right)+\sum_{s \notin s^{D}} \lambda_{3 s}^{B, n o-r u n}\left(1+r^{D}\right)<0
\end{aligned}
$$

using equations (32), (30) and (65).Thus, $x_{e q}^{B}=0$.

Proposition 3: $P$ does not issue equity claims on the output of the risky project when $V_{3 g}^{I}=1$ and $V_{3 m}^{I}, V_{3 b}^{I}<1$ and $x_{e q}^{R}>0$.

Proof. We prove the result by contradiction. Suppose that $P$ is willing to issue $y$ shares at the price $p$ per share and that his own contribution is $I^{P}$ equally divided into the same amount of shares with nominal price 1 . The payoff from the project to the entrepreneur in state $3 g$, if his project is not liquidated early, is $\frac{I^{P}}{I^{P}+y}\left[A_{2 g} F\left(I+I^{P}+p \cdot y\right)-I\left(1+r^{I}\right)\right]$. Conditional on a bank-run the payoff $P$ receives from her equity investment is $\xi \cdot\left(I^{P}+p \cdot y\right) \frac{I^{P}}{I^{P}+y}$. The optimality condition for $y$ is, thus, $\lambda_{3 g}^{P, \text { no-run }}\left[-\frac{I^{P}}{\left(I^{p}+y\right)^{2}} A_{2 g}\left(I+I^{P}+p \cdot y\right)^{a}+\frac{I^{P}}{I^{P}+y} a A_{2 g}\left(I+I^{P}+p \cdot y\right)^{a-1} \cdot p\right]+\xi \frac{(p-1) I^{P}}{\left(I^{P}+y\right)^{2}} I^{P} \sum_{s} \lambda_{3 s}^{P, r u n}=$ 0 . Thus,

$$
p_{y=0}=\frac{\xi \cdot \sum_{s} \lambda_{3 s}^{P, r u n}+\lambda_{3 g}^{P, n o-r u n} A_{3 g}\left(I+I^{P}\right)^{a}\left(I^{P}\right)^{-1}}{\xi \cdot \sum_{s} \lambda_{3 s}^{P, r u n}+\lambda_{3 g}^{P, n o-r u n} a A_{3 g}\left(I+I^{P}\right)^{a-1}}
$$

evaluated at $y=0$ and the dividends per share are $\frac{(1-a) A_{3 g}\left(I+I^{P}\right)^{a}}{I^{P}}$. 
$R$ is willing to buy equity in $P^{\prime} s$ project if

$$
p_{y=0} \cdot \lambda_{1}^{R}<\left(\frac{\lambda_{2}^{R, i, n o-r u n}+\lambda_{2}^{R, p, n o-r u n}}{\lambda_{2}^{R, p, n o-r u n}}\right) \lambda_{3 g}^{R} \frac{(1-a) A_{3 g}\left(I+I^{P}\right)^{a}}{I^{P}}+\xi \cdot\left(\lambda_{2}^{R, \text { run }, \text { paid }}+\lambda_{2}^{R, \text { run }, \text { unpaid }}\right),
$$

allowing for a secondary marker where equity in the entrepreneurial firm can be traded. Using equation (17) and (20), condition (68) can be written as

$$
p_{y=0} \cdot \sum_{s} \lambda_{3 s}^{R, p . n o-r u n} D P S_{3 s}<\lambda_{3 g}^{R} \frac{(1-a) A_{3 g}\left(I+I^{P}\right)^{a}}{I^{P}}+\xi \cdot \frac{\lambda_{2}^{R, \text { run,paid }}+\lambda_{2}^{R, \text { run,unpaid }}}{\lambda_{2}^{R, i, n o-\text { run }}+\lambda_{2}^{R, p, \text { no-run }}} .
$$

Consider the case that the probability of a bank-run is zero. Then, (67) yields $p_{y=0}=\frac{1}{a} \frac{\left(I+I^{P}\right)^{a-1}}{I^{P}}$ and, using (69), $R$ will invest in entrepreneurial equity if

$$
\begin{aligned}
& \sum_{s} \lambda_{3 s}^{R, p . n o-r u n} D P S_{3 s}<\lambda_{3 g}^{R}(1-a)\left(1+r^{I}\right) \\
& \lambda_{3 g}^{R}(1-\delta) D^{R}\left(r^{I}-r^{D}\right)+a \lambda_{3 g}^{R}\left(1+r^{I}\right)+E Q \lambda_{3 m}^{R} D P S_{2 m}<0,
\end{aligned}
$$

which is a contradiction. Hence, $R$ will not invest in equity. This is also true for $q>0$ because the equity investment in $P$ becomes less profitable, as there is a positive probability that it will be liquidated, and yields an inefficient return dominated by investment in deposits or the liquid asset.

Similarly, $B$ is not willing to buy equity in $P^{\prime} s$ project given her optimality condition (31). 


\section{Appendix B}

Table 18: Exogenous variables

\begin{tabular}{lllll}
\hline$e_{1}^{P}=1.00$ & $e_{1}^{R}=10.00$ & $e_{1}^{B}=0.70$ & $E^{B}=0.20$ & $\omega_{3 g}=0.50$ \\
$e_{3 g}^{P}=1.00$ & $e_{2}^{R}=4$ & $e_{3 g}^{B}=1.50$ & $\alpha=0.7$ & $\omega_{3 m}=0.40$ \\
$e_{3 m}^{P}=1.00$ & & $e_{3 m}^{B}=1.50$ & $A_{3 g}=3.30$ & $\omega_{3 b}=0.10$ \\
$e_{3 b}^{P}=0.40$ & & $e_{3 b}^{B}=1.50$ & $A_{3 m}=1.90$ & $\delta=0.2$ \\
$\gamma^{P}=2.10$ & $\gamma^{R}=2.10$ & $\gamma^{B}=2.10$ & $A_{3 b}=0.40$ & $\xi=0.5$ \\
\hline \hline
\end{tabular}

Table 19: Equilibrium variables

\begin{tabular}{|c|c|c|c|c|c|}
\hline \multicolumn{3}{|c|}{ Financial Variables } & \multicolumn{3}{|c|}{ Consumption \& Utilities } \\
\hline & Limited & Unlimited & & Limited & Unlimited \\
\hline & Liability & Liability & & Liability & Liability \\
\hline$r^{I}$ & 0.745 & 0.000 & $c_{1}^{P}$ & 1.000 & 0.958 \\
\hline$r_{3}^{D}$ & 0.570 & 0.000 & $c_{3 g}^{P, \text { no-run }}$ & 2.906 & 2.272 \\
\hline$r_{2}^{D}$ & 0.000 & 0.000 & $c_{3 m}^{P, n o-r u n}$ & 1.000 & 1.602 \\
\hline$V_{3 m}^{I}$ & 0.823 & 1.000 & $c_{3 b}^{P, \text { no-run }}$ & 0.400 & 0.284 \\
\hline$V_{3 b}^{I}$ & 0.173 & 1.000 & $c_{3 g}^{P, \text { run }}, c_{3 m}^{P, \text { run }}$ & 1.000 & - \\
\hline$V_{3 b}^{D}$ & 0.226 & 1.000 & $c_{3 m}^{P, \text { run }}$ & 0.400 & - \\
\hline$I$ & 2.548 & 0.308 & $c_{1}^{R}$ & 7.109 & 7.000 \\
\hline$L I Q_{1}$ & 0.543 & 0.027 & $c_{2}^{R, i, n o-r u n}$ & 6.943 & 7.000 \\
\hline$L I Q_{2}$ & 0.000 & 0.000 & $c_{3 g}^{R, p, n o-r u n}$ & 8.813 & 7.000 \\
\hline$D^{R}$ & 2.715 & 0.134 & $c_{3 m}^{R, p, n o-r u n}$ & 8.350 & 7.000 \\
\hline$x_{e q}^{R}$ & 0.176 & 0.000 & $c_{3 b}^{R, p, n o-r u n}$ & 4.905 & 7.000 \\
\hline$D P S_{3 g}$ & 2.752 & 1.000 & $c_{2}^{R, r u n, p a i d}$ & 6.715 & - \\
\hline$D P S_{3 m}$ & 0.656 & 1.000 & $c_{2}^{R, \text { run,unpaid }}$ & 4.000 & - \\
\hline$D P S_{3 b}$ & 0.000 & 0.000 & $c_{1}^{B}$ & 0.700 & 0.700 \\
\hline$C R$ & 0.148 & 0.650 & $c_{3 g}^{B, n o-r u n}$ & 2.050 & 1.700 \\
\hline$L R$ & 0.213 & 0.087 & $c_{3 m}^{B, n o-r u n}$ & 1.631 & 1.700 \\
\hline$\theta$ & 0.669 & 1.344 & $c_{3 b}^{B, n o-r u n}$ & 1.500 & 1.700 \\
\hline$q$ & 0.109 & 0.000 & $c_{3 s}^{B, \text { run }}$ & 1.500 & - \\
\hline$L I Q_{1}^{R}$ & 0.000 & 2.866 & $\bar{U}^{P}$ & -1.697 & -1.716 \\
\hline$L I Q_{2}^{R}$ & 3.943 & 6.866 & $\bar{U}^{R}$ & -0.206 & -0.214 \\
\hline$I^{P}$ & 0.000 & 0.042 & $\bar{U}^{B}$ & -1.834 & -1.853 \\
\hline
\end{tabular}



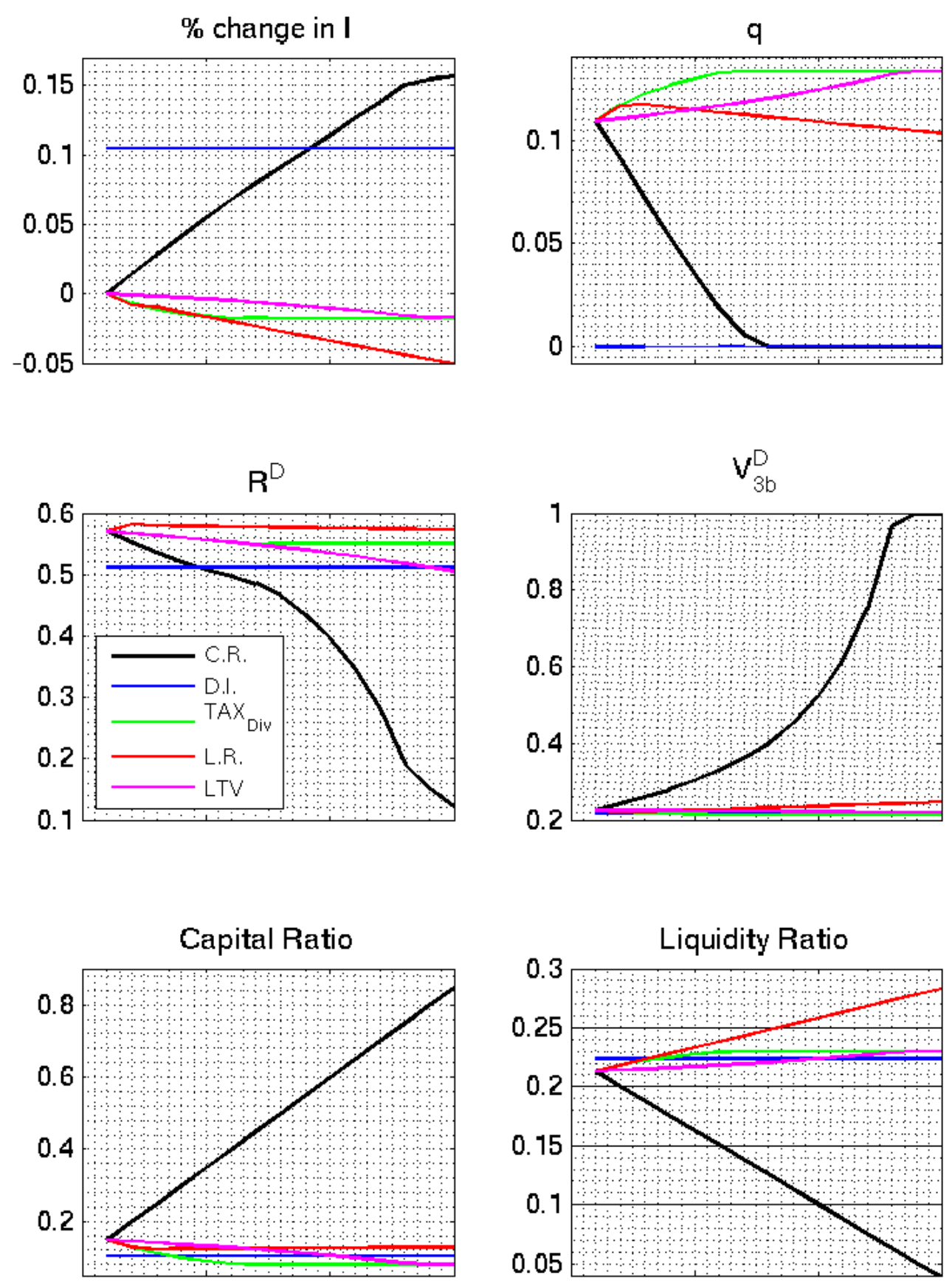

Figure 2: Comparative statics for single regulations: The figure shows the response of selected variables for different levels of various regulations. The horizontal axis represents the number of successive times each tool is tightened. The first iteration correspond to the competitive equilibrium level where the tool is not binding (except for deposit insurance which is a binary decisions). 

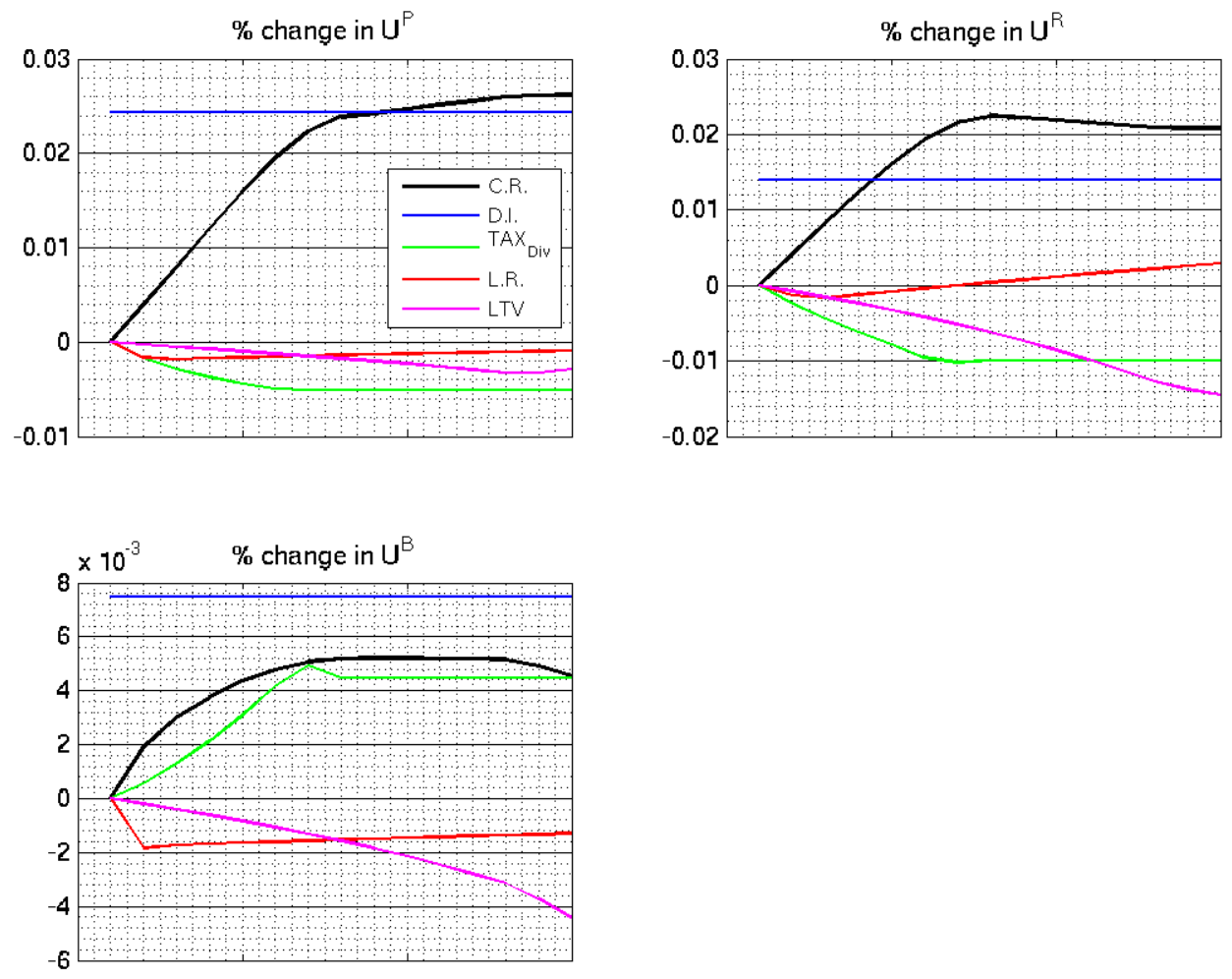

Figure 3: Comparative statics for single regulations: The figure shows the change in agents' welfare for different levels of various regulations compared to the competitive equilibrium. The horizontal axis represents the number of successive times each tool is tightened. The first iteration correspond to the competitive equilibrium level where the tool is not binding (except for deposit insurance which is a binary decisions).
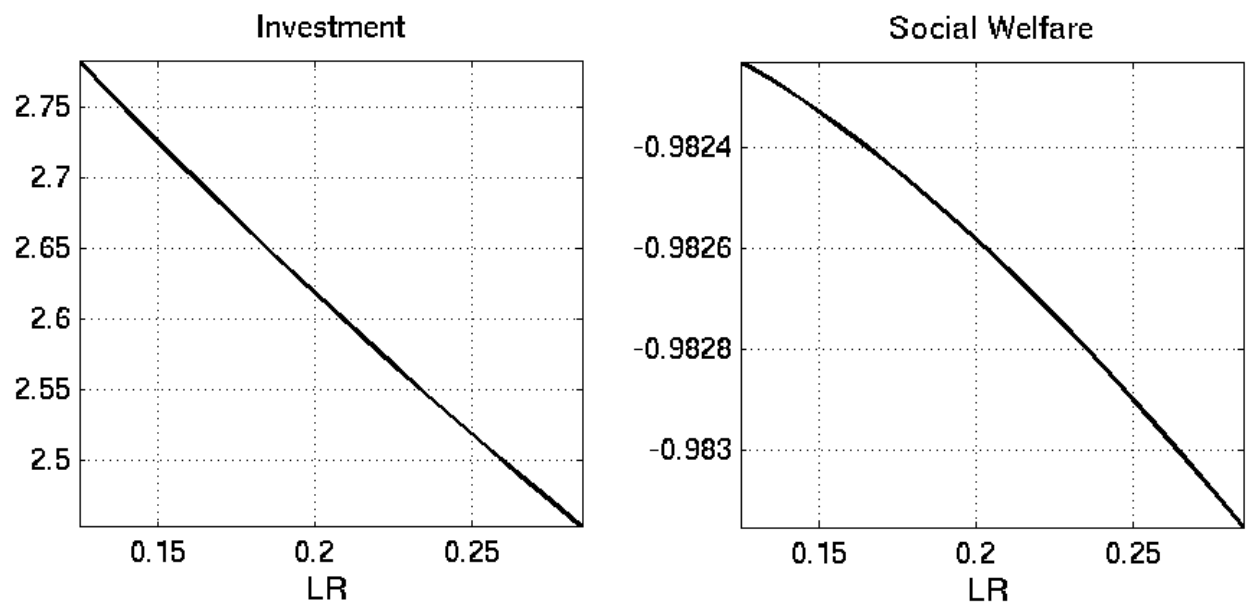

Figure 4: Risky investment (left) and social welfare (right) for stricter liquidity requirements under optimal capital regulation $\left(w^{P}=0.35, w^{R}=0.35\right)$. 